Türkiye için Alternatif Bir Anlayış: Kültürel Değerlere Duyarlı Eğitim*

\title{
Nihat KOTLUK ${ }^{* *}$, Serhat KOCAKAYA***
}

Öz: Bu çalışmanın amacı, Kültürel Değerlere Duyarlı Eğitim (KDDE) anlayışını literatüre dayalı olarak kapsamlı bir şekilde incelemek ve KDDE'yi Türkiye'nin sahip olduğu kültürel farklılıklar bağlamında Türkiye için alternatif bir eğitim anlayışı olarak tartışmaktır. Araştırma, nitel araştırma yöntemlerinden doküman analizine dayalı olarak yapılmıştır. Veriler, araştırmacılar tarafından yaklaşık üç yıl süren (2015-2018) ulusal ve uluslararası alan yazın taramaları sonucu toplanmıştır. Araştırmada KDDE'nin önemli temsilcilerine ait 15 makale ve 5 kitap temel veri kaynağı olarak kullanılmıştır. Araştırmalar sonucunda; Türkiye Eğitim Sistemi içerisinde engellilik, sosyoekonomik düzey, etnik kimlik, anadil, dini inanç gibi kültürel ve bireysel farklılıklara sahip çok sayıda öğrenci bulunduğu, Türkiye'de eğitimde eşitsizliğin; cinsiyet, yaşanılan yerleşim yeri (kır ya da kent), kardeş sayısı, evde konuşulan dil, okul türleri, okulların devlet okulu veya özel okul olup olmaması, sosyoekonomik altyapı ve öğrencilerin bulunduğu coğrafi bölgeler gibi birçok faktöre bağlı olduğu, Türkiye'de farklı okul ve kademelerde öğrenim gören mülteci öğrenci sayısının bir hayli fazla olduğu ve eğitim sisteminde bu tür farklılıklardan dolayı birçok problem yaşandığı belirlenmiştir. Türkiye'nin sahip olduğu kültürel farklılıklar, çokkültürlü yapı, eğitim sisteminde bulunan engelli ve mülteci öğrenci sayısı, eğitimde eşitsizlik raporları, herkes için eğitim ve eğitimde feda edilecek tek bir fert yoktur anlayışı doğrultusunda; Türkiye'de daha kapsayıcı alternatif eğitim

\footnotetext{
* Çalışmanın bir kısmı Ekim 2016' da Antalya' da düzenlenen 4. Uluslararası Eğitim Programları ve Öğretim Kongresi'nde sözlü bildiri olarak sunulmuştur. Çalışma, Nihat Kotluk' un doktora tezinden üretilmiştir.

** Dr. Bağımsız Araştırmacı, Eğitim Bilimleri. https://orcid.org/0000-0002-4314-9492 nihatkotluk@gmail.com

*** Doç. Dr. Yüzüncü Yıl Üniversitesi Eğitim Fakültesi, Matematik ve Fen Bilimleri Eğitimi Anabilim Dalı, Fizik Eğitimi Bilim Dalı. https://orcid.org/0000-0002-5576-3780 skocakaya@gmail.com
}

\begin{tabular}{lll}
\hline Gönderim: 08.04.2018 & Kabul:26.07.2018 & Yayın:10.09.2018 \\
\hline
\end{tabular}


anlayışlarına ihtiyaç olduğu söylenebilir. Özellikle eğitimde firsat eşitliği ve eğitimde kültürel farklılıklar bağlamında Kültürel Değerlere Duyarlı Eğitim anlayışı bu ihtiyaçlara cevap verebilir. Bu çalışmanın, özellikle benzer konularda çalışma yapacak araştırmacılara, eğitim programcılarına, öğretmen eğitimcilerine ve eğitim politikacılarına teorik anlamda kaynak teşkil etmesi beklenmektedir.

Anahtar Kelimeler: Kültürel Farklılıklar, Kültürel Değerlere Duyarlı Eğitim, Pedagoji, Öğretim, Öğretmen yeterlikleri.

\section{An Alternative Approach for Turkey: Culturally Relevant/Responsive Education}

Abstract: The purpose of this study is to introduce and discuss Culturally Relevant/Responsive Education (CRE), which can be seen as an alternative approach for Turkey, in the context of students' diversity in Turkey and related literature. Based on document analysis of the qualitative research methods, the researchers examined the articles, books, reports etc. downloaded from the university database, for about 3 years (2015-2018), for the purposes of the study. Based on the findings; Turkey, as it is in every period of history, is a multicultural country, that has hosted many different cultures with its 7 geographical regions and 81 provinces. Also, there are many students who have different disabilities and need special education in Turkey's Educational System. On the other hand, the number of refugee students has been increasing dramatically in Turkey, for the last 5 years. According to the reports about equity in education in Turkey, there is achievement gap among students regarding gender, life in rural or urban areas, the number of siblings, home language, school types, socioeconomic levels, and geographic regions. In line with education for all, equity in education and equality of educational opportunity, it is important to arrange teaching-learning process in such a way that it should include all these students. Thus, in order to be more inclusive in education, it can be said that there is a need for an alternative approach for Turkey and CRE may be relevant. It is expected that this study will be a resource for teachers, educators, and policymakers who are 
interested in educating the students who are culturally, socially, economically, and linguistically different and for researchers who are interested in CRE in Turkey.

Key Words: Cultural Diversity, Culturally Relevant Pedagogy, Culturally Responsive Teaching, Teachers Competence, Culturally Relevant Education in Turkey.

\section{Giriş}

Her toplum farklı bireylerden ve kültürlerden oluşmaktadır. Benzer şekilde Türkiye, 7 coğrafi bölgesi, 81 iliyle tarihin her döneminde farklı medeniyetlere ev sahipliği yapmış ve çokkültürlü bir yapıda olmuştur. Diğer taraftan Türkiye Eğitim Sistemi'nde göz ardı edilemeyecek sayıda farklı engellere sahip öğrenciler bulunmaktadır. Bununla birlikte özellikle son 5 yılda Türkiye'de öğrenim gören mülteci öğrenci sayısı giderek artmaktadır. Yine ilgili araştırmalar incelendiğinde, Türkiye'de eğitimde eşitsizliğin birçok faktöre bağlı olduğu görülmektedir. Dolayısıyla Türkiye Eğitim Sistemi içerisinde dil, din, inanç, etnik kimlik vb. pek çok farklı kültürel değere ve engellilik, kardeş sayısı, sosyoekonomik düzey gibi farklılıklara sahip öğrenciler bulunmaktadır.

Örneğin KONDA araştırma şirketinin 2006, 2007 ve 2011 yıllarında yaptığı araştırmalarda; Türkiye'de insanların yaklaşık \% 85'inin Türkçe, \% 13'ünün Kürtçe ve Zazaca, \% 2'sinin Arapça olmak üzere Türki diller, Balkan dilleri, Lazca, Çerkezce, Ermenice, Kafkas dili, Rumca gibi dilleri konuştuğu; Türkiye'nin yaklaşık \% 78'inin Türk, \% 13'ünün Kürt ve \% 1.5'unun Laz olmak üzere 36 farklı etnik kökeni barındırdığı; Türkiye'de Müslüman, Hıristiyan ve Yahudi gibi birçok dinin bir arada yaşadığı belirtilmiştir. Dolayısıyla Türkiye'nin kültürel farklılıkları bir arada tutabilen yapısıyla tarihin her döneminde olduğu gibi şimdi de önemli bir kültürel mirasa ve zenginliğe sahip olduğu rahatlıkla söylenebilir (Memduhoğlu, 2008).

Milli Eğitim Bakanlığı (MEB) verilerine göre ise; 2016-2017 eğitim-öğretim yılı 2 Mayıs 2017 tarihi itibariyle Türkiye genelinde özel eğitim -resmî ve özel dâhil olmak üzere- 
okullarında ilkokul, ortaokul ve meslek lisesinde 45.590 öğrenci, ilkokul ve ortaokulda özel eğitim sınıflarında 40.887 öğrenci, ana sınıfı, ilkokul, ortaokul ve lisede kaynaştırma eğitimi alan 219.728 öğrenci olmak üzere toplam 306.205 engelli öğrenci eğitim-öğretim görmektedir (MEB, 2017a). Bu açıdan bakıldığında özellikle eğitimde feda edilecek tek bir fert yoktur anlayışı doğrultusunda hareket edilmesi büyük önem arz etmektedir.

Diğer taraftan Türkiye özellikle son 4-5 yıldır 3 milyondan fazla mülteciye ev sahipliği yapmaktadır. Çoğunluğu Suriyeli olmak üzere Irak, Afganistan başta olmak üzere mülteci ve sığınmacı sayısı hızla artmaktadır. Bu durum eğitim sistemini de etkilemektedir. Örneğin Türkiye'de Geçiş Eğitim Merkezleri ve devlet okullarında 500 bine yakın mülteci-sı̆ğınmacı öğrenci bulunmaktadır. Şehirler düzeyinde bakıldığında en fazla İstanbul (29.147 ) ve en az Bartın (2) olmak üzere Türkiye'nin her şehrinde eğitim sistemine kayıtlı mülteci veya sı̆̆ınmacı öğrenci yer almaktadır (Eğitim Reformu Girişimi, 2017). Araştırmalar, öğretmenlerin mülteci öğrencilerin eğitim-öğretim süreçlerinde, dil, uygun öğretim içeriğini hazırlanma, öğretme stratejileri, ders araç gereçleri, ölçme ve değerlendirme, iletişim kurma gibi başlıklar altında birçok problemle karşılaştıklarını göstermektedir (Erdem, 2017) Öğrencilerin ise genellikle kültürel uyumsuzluktan dolayı dışlanma, yalnızlık, içe kapanma gibi sorunlar yaşadıkları belirtilmektedir (Kultas, 2017).

Ayrıca, Türkiye'de eğitimde firsat eşitliği veya eğitimde eşitsizlik ile ilgili araştırmalar (Ataç, 2017; Oral ve McGivney, 2014) incelendiğinde, eğitimde eşitsizliğin en önemli sebebi sosyoekonomik düzey olarak görülse de firsat ve imkan eşitsizliğinin ayrıca; cinsiyet, yaşanılan yerleşim yeri (kır ya da kent), kardeş sayısı, evde konuşulan dil, okul türleri, okulların devlet okulu veya özel okul olup olmaması, sosyoekonomik altyapılar ve öğrencilerin bulunduğu coğrafi bölgeler gibi birçok faktöre bağlı olduğu görülmektedir. Örneğin Ataç (2017), Türkiye'de okul türleri ve coğrafi bölge açısından dezavantajlı grupların bulunduğunu, 
üniversiteden mezun olma durumunun coğrafi ve okul temelli eşitsizliklere bağlı olduğunu belirtmiştir.

Benzer şekilde, Oral ve McGivney (2014) çalışmalarında; akademik başarı ile sosyoekonomik düzey arasında güçlü bir ilişki olduğunu, Türkiye'de en yüksek sosyoekonomik dilimden gelen 15 yaş grubundaki öğrencilerin ağırlıklı olarak fen liseleri ya da Anadolu liselerine gittiğini ve meslek liselerindeki öğrencilerin \% 23 'ünün ise en düşük \% 20'lik sosyoekonomik dilimden geldiğini belirtilmişlerdir. Araştırmada, okul terklerinin ise tüm bölgelerde ciddi sorun alanları olarak ve özellikle erkek öğrencilerde öne çıktığı, ortaöğretim çağında olan ve kırsal bölgede yaşayan gençlerin okullulaşma oranının kentte yaşayanlara oranla \% 15 daha düşük olduğu belirtilmiştir. Yine araştırmada; evlerinde Türkçe konuşulan çocukların konuşulmayan akranlarına oranla ortalama iki okul yılı ileride performans gösterdiği, öğrencinin kardeş sayısı arttıkça ortaöğretimde okullulaşma olasıllı̆̆ının \% 2 civarında düştüğü, son olarak kalabalık ailelerden gelen kızların ortaöğretime katılma olasılıklarının daha düşük olduğu belirtilmiştir.

Tüm bu veriler 1şığında eğitimde eşitliğin ve başarının sağlanması, eğitimde ayrımcılık, ötekileştirme, eğitimden ayrılma gibi istenmeyen durumlarla mücadele edilmesi ve eğitim sisteminin daha kapsayıcı olması adına Türkiye'de eğitim sisteminin kültürel değerlere ve farklılıklara uygun bir şekilde düzenlenmesi herkes için eğitim açısından önem arz etmektedir. Çünkü cinsiyet, engellilik, kardeş sayısı, coğrafi bölge, dil, din, inanç, ırk, etnik köken, sosyoekonomik düzey gibi kültürel farklılıklara rağmen tüm öğrencilerin başarılı olması ve barış içinde yaşaması Türkiye'nin geleceği açısından önemlidir.

Fakat, Türkiye'de hem eğitim sisteminde hem de öğretmen yetiştirme yaklaşımlarında kültürel farklılıkların yeterince dikkate alınmadığı ve çokkültürlü eğitim, kültürel değerlere duyarlı pedagoji, kültürel değerlere duyarlı öğretim veya kültürel değerlere duyarlı eğitim bağlamında uygun bir anlayışın yeterince hakim olmadığı söylenebilir. Diğer taraftan 
Türkiye'de öğretmen atamaları, merkezi bir sistemle, KPSS sonuçları üzerinden yapıldığından, öğretmenlerin hem kendi kültürüne benzer hem de kendi kültüründen çok farklı bir kültürde yetişen öğrencilerin bulunduğu bölgelerde, okullarda ve sinıflarda görev yapma ihtimalleri yüksektir. Öğretmenler kendi kültürlerinde görev yapsalar bile sınıflarında en düşük ihtimalde bile sosyoekonomik açıdan farklı veya farklı engellere sahip kaynaştırma öğrencilerinin olması kaçınılmazdır.

$\mathrm{Bu}$ perspektiften hareketle, öğrencilerin kültürlerini, duygusal ve sosyal altyapılarını, bilişsel şemalarını, yani farklı kültürel değerlerini ve bireysel farklılıklarını eğitim sistemlerine, öğrenme ve öğretme süreçlerine dahil ederek, ayrım gözetmeksizin tüm öğrencileri üst düzey becerilere sahip bir şekilde yetiştirmeye yönelik eğitim, günümüzde geniş çevrelerce tartış1lan ve bu çalışmanın kuramsal temellerini oluşturan Kültürel Değerlere Duyarlı Eğitim'dir (KDDE) (Culturally Relevant/Responsive/Sustaining Education) (Ladson-Billings, 1995a; 1995b; 2009; Gay, 2002a; 2018; Paris, 2012; Paris ve Alim, 2017; Dover, 2013; Aronson ve Laughter, 2015).

Fakat bu çalışma için araştırmacılar tarafından yapılan literatür taramasında; Türkiye'de çokkültürlü eğitim dışında özellikle KDDE ile ilgili az sayıda teorik çalışma (Kotluk ve Kocakaya, 2016; Karataş ve Oral, 2016), bir eylem araştırması (Tuncel, 2017), öğretmenlerin öz-yeterlik algısını belirlemeye yönelik bir ölçek geliştirme çalışması (Kotluk ve Kocakaya, 2017b) ve bir kitap çevirisi (Gay, 2014; Çev Ed: H. Aydın) dışında bu konuda yapılan çalışmalarla karşılaşılmamıştır. Kotluk'un (2018), Kotluk ve Kocakaya'nın (2016; 2017a; 2017b) belirttiği gibi, Türkiye'de KDDE ile ilgili özellikle araştırmacıların ve öğretmenlerin teorik olarak faydalanabileceği detaylı Türkçe literatüre ihtiyaç duyulmaktadır. Bu çalışma ile bu ihtiyacın kısmen de olsa karşılanması beklenmektedir.

\section{Araştırmanın Amacı}


Bu çalışmanın amacı, Türkiye'nin kültürel farklılıkları, çeşitliliği, mirası ve öğrencilerin sahip olduğu engellilik, cinsiyet, sosyoekonomik düzey, kardeş sayısı, dil, coğrafi bölge vb. farklılıklar bağlamında alternatif bir yaklaşım olarak görülebilecek Kültürel Değerlere Duyarlı Eğitim anlayışını alan yazına dayalı olarak tartışmaktır. Bu doğrultuda araştırmanın soruları şu şekildedir:

1. Kültürel Değerlere Duyarlı Eğitim nedir, neyi amaçlamaktadır?

2. Kültürel Değerlere Duyarlı Öğretim nedir?

3. Kültürel Değerlere Duyarlı Pedagoji nedir?

4. Kültürel Değerlere Duyarlı Eğitim ile Çokkültürlü Eğitim, Eleştirel Pedagoji ve Eşitlik Pedagojisi arasında nasıl bir ilişki vardır?

5. Kültürel Değerlere Duyarlı Öğretmen ne demektir, yeterlikleri nelerdir ve Türkiye'de öğretmen yeterlikleri ile kıyaslandığında benzerlik ve farklılıklar nelerdir?

\section{Araştırmanın Önemi}

Türkiye Eğitim Sistemi'nde yer alan farklılıklara rağmen şu ana kadar yapılmamış olması nedeniyle özellikle bu çalışmanın, bu konuda çalışma yapacak araştırmacılara, eğitimöğretim ortamında farklı kültürel değerlere sahip öğrencilerle her gün karşılaşan öğretmenlere, öğretmen eğitimcilerine, eğitim programcıları ve politikacılarına kaynak teşkil etmesi beklenmektedir.

$\mathrm{Bu}$ araştırmanın bulgu, sonuç ve önerilerinin genelde eğitim sistemini özelde ise öğretmen eğitim programlarını kültürel açıdan daha duyarlı ve kapsayıcı hale getirme çabalarına hizmet etmesi ve yapılacak düzenlemelere teorik ve pratik katkılar sunması beklenmektedir.

\section{Yöntem}


Çalışma, nitel araştırma yöntemlerinden doküman analizine dayalıdır. Doküman analizinde Yıldırım ve Şimşek'in (2013) aktardığı aşağıdaki aşamalar takip edilmiştir.

a) Dokümanlara Ulaşma: Çalışmada SSCI indeksli dergilerden culturally relevant pedagogy, culturally responsive teaching, culturally responsive instruction, culturally sustaining pedagogy, multicultural education, equity pedagogy, critical pedagogy, culturally relevant education terimleri ile tarama yapılarak İngilizce makalelerin tam metinleri toplanmıştır. Ayrıca KDDE'nin önemli temsilcilerinden Gloria Ladson-Billings'in (2009) The Dreamkeepers: Successful Teachers of African American Children, Geneva Gay'in (2018, 3rd edition) Culturally Responsive Teaching: Theory, Research and Practice ve Paris \& Alim'in (2017) Culturally Sustaining Pedagogies: Teaching and learning for justice in a changing world adlı kitapları yurtdışından istenerek ayrıntılı bir şekilde incelenmiştir.

b) Orijinalliği Kontrol Etme: Makale ve kitapların orijinalliğini ve güvenirliğini sağlamak amacıyla öncelikle uluslararası indekslerde en fazla atıf alan alanın önde gelen temsilcileri belirlenmiş ve bu yazarların SSCI indeksli dergilerden makalelerinin seçilmesine özen gösterilmiştir.

c) Dokümanları Anlama: Makale ve kitaplar tek tek incelenmiş, araştırmacılar tarafından araştırmanın 5 sorusu doğrultusunda önceden belirlenen ve bulgular bölümünde sunulacak olan temalar altında veriler toplanmıştır.

d) Verileri Analiz Etme: Araştırmanın soruları doğrultusunda toplanan veriler araştırmacılar tarafından analiz edilmiş ve sadeleştirilmiştir.

e) Verileri Kullanma: Son aşamada elde edilen, güvenirlik ve geçerlik çalışmaları sağlanan bilgiler bu araştırmada yayınlanmak üzere makale haline getirilmiştir. 
Çalışmada 15 makale ve 5 kitap ana kaynak olarak kullanılmıştır (Tablo 1). Bununla birlikte Türkiye'de özellikle kültür ve eğitim ilişkisi, eğitimin kültürel/toplumsal/sosyolojik temelleri, eğitimde eşitsizlik raporları ve çokkültürlü eğitim ile ilgili yapılan çalışmalardan faydalanılmıştır. Çalışmada yararlanılan tüm kaynaklar kaynakçada verilmiştir.

Araştırmada verilerin güvenirliğini sağlamak amacıyla öncelikle uluslararası indekslerde en fazla atıf alan ve alanın önde gelen temsilcileri belirlenmiş ve bu yazarların SSCI indeksli dergilerden makalelerinin seçilmesine özen gösterilmiştir. Ayrıca yayın dili İngilizce olan bu çalışmaların tamamında anadili Türkçe olan fakat ileri düzeyde İngilizce bilen, çokkültürlülük, kültürel değerlere duyarlı eğitim konularında uzman olan ve hem yurtiçinde hem de yurtdışında bu alanda ders veren bir uzman öğretim üyesinden yapılan çevirilerin doğruluğu noktasında uzman görüşü alınmıştır.

Tablo 1. Çalışmada kullanılan ana kaynaklar

\begin{tabular}{|c|c|c|}
\hline \multirow{10}{*}{$\frac{a}{3}$} & 1. & $\begin{array}{l}\text { Au, K. H. (2007). Culturally responsive instruction: Application to multiethnic } \\
\text { classrooms. Pedagogies: An International Journal, 2(1), 1-18. }\end{array}$ \\
\hline & 2. & $\begin{array}{l}\text { Banks, C. A. M \& Banks, J. A. (1995) Equity pedagogy: An essential component of } \\
\text { multicultural education, Theory Into Practice, } 34 \text { (3), 152-158 }\end{array}$ \\
\hline & 3. & $\begin{array}{l}\text { Brown, J. C. (2017). A metasynthesis of the complementarity of culturally responsive and } \\
\text { inquiry-based science education in K-12 settings: Implications for advancing } \\
\text { equitable science teaching and learning. Journal of Research in Science } \\
\text { Teaching, 54(9), 1143-1173. }\end{array}$ \\
\hline & 4. & $\begin{array}{l}\text { Gay, G. (2002a). Preparing for culturally responsive teaching. Journal of Teacher } \\
\text { Education, } 53(2), 106-116 \text {. }\end{array}$ \\
\hline & 5. & $\begin{array}{l}\text { Gay, G. (2002b). Culturally responsive teaching in special education for ethnically diverse } \\
\text { students: setting the stage. Qualitative studies in education, 6, 613-629 }\end{array}$ \\
\hline & 6. & Gay, G. (2013). Teaching to and through cultural diversity, Curriculum Inquiry, 43:1 \\
\hline & 7. & $\begin{array}{l}\text { Keehne, C. N., Sarsona, M. W., Kawakami, A. J., \& Au, K. H. (2018). Culturally Responsive } \\
\text { Instruction and Literacy Learning. Journal of Literacy Research, 50(2), 141-166 }\end{array}$ \\
\hline & 8. & $\begin{array}{l}\text { Ladson-Billings, G. (1992b). Liberatory consequences of Literacy: A case of culturally } \\
\text { relevant instruction for African American students. Journal of Negro Education, 61, } \\
\text { 378-391. }\end{array}$ \\
\hline & 9. & $\begin{array}{l}\text { Ladson-Billings, G. (1992c). Reading between the lines and beyond the pages: A culturally } \\
\text { relevant approach to literacy teaching. Theory into Practice, 31(4), 312-320 }\end{array}$ \\
\hline & 10. & $\begin{array}{l}\text { Ladson-Billings, G. (1995a). But that's just good teaching! The case for culturally relevant } \\
\text { pedagogy. Theory into Practice, } 34,159-165\end{array}$ \\
\hline
\end{tabular}




\begin{tabular}{|c|c|c|}
\hline & 11. & $\begin{array}{l}\text { Ladson-Billings, G. (1995b). Toward a theory of culturally relevant pedagogy, American } \\
\text { Educational Research Journal, 32(3), 465-491. }\end{array}$ \\
\hline & 12. & $\begin{array}{l}\text { Ladson-Billings, G. (2014). Culturally relevant pedagogy 2.0: The remix. Harvard } \\
\text { Educational Review, 84(1), p. 74-84. }\end{array}$ \\
\hline & 13. & $\begin{array}{l}\text { Mensah, F. M. (2011). A case for culturally relevant teaching in science education and } \\
\text { lessons learned for teacher education. Journal of Negro Education, 80(3), 296-309. }\end{array}$ \\
\hline & 14. & $\begin{array}{l}\text { Paris, D. (2012). Culturally sustaining pedagogy: A needed change in stance, terminology, } \\
\text { and practice. Educational Researcher, } 41,93-97 .\end{array}$ \\
\hline & 15. & $\begin{array}{l}\text { Villegas, A., \& Lucas, T. (2002). Preparing culturally responsive teachers: Rethinking the } \\
\text { curriculum. Journal of Teacher Education, 53(1), 20-32. }\end{array}$ \\
\hline & 1. & $\begin{array}{l}\text { Banks, J. A., \& Banks, C. A. M. (Eds.). (2010). Multicultural education: Issues and } \\
\text { perspectives (7th ed.). Hoboken, NJ: John Wiley. }\end{array}$ \\
\hline & 2. & $\begin{array}{l}\text { Gay, G. (2018). Culturally responsive teaching: Theory, research, and practice. (3rd } \\
\text { Ed.).Teachers College Press. }\end{array}$ \\
\hline & 3. & $\begin{array}{l}\text { Ladson-Billings, G. (2009). The dreamkeepers: Successful teachers of African American } \\
\text { children. San Francisco, CA: Jossey Bass Publishers. }\end{array}$ \\
\hline E & 4. & $\begin{array}{l}\text { Nieto, S. (2002). Language, culture, and teaching: Critical perspectives for a new century. } \\
\text { Mahway, NJ: Lawrence Erlbaum. }\end{array}$ \\
\hline 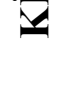 & 5. & $\begin{array}{l}\text { Paris, D. \& Alim, H. S. (2017). Culturally sustaining pedagogies: Teaching and learning } \\
\text { for justice in a changing world. Teachers College Press. }\end{array}$ \\
\hline
\end{tabular}

\section{Bulgular}

\section{Kültürel Değerlere Duyarlı Ĕ̆itim nedir, neyi amaçlamaktadır?}

\section{Kültürel Değerlere Duyarlı Eğitim (Culturally Relevant/Responsive Education)}

Öğrencilerin kültürlerini, duygusal ve sosyal altyapılarını, bilişsel şemalarını, deneyimlerini ve dil, etnisite gibi farklı kültürel değerlerini eğitim sistemlerine, öğrenme ve öğretme süreçlerine dahil ederek, tüm öğrencileri üst düzey becerilere sahip bir şekilde yetiştirmeye yönelik eğitim; Kültürel Değerlere Duyarlı Eğitim'dir (Culturally Relevant/Responsive/Sustaining Education). KDDE, birçok araştırmacı tarafından farklı kültürel değerlere sahip öğrencilerin sosyal ve akademik ihtiyaçlarının karşılanmasına yönelik etkili bir eğitim olarak tanımlanmaktadır (Ladson-Billings, 1995a; 1995b; 2009; Gay, 2002a; 2018; Paris, 2012; Paris ve Alim, 2014; Dover, 2013; Aronson ve Laughter, 2015).

Kültürel Değerlere Duyarlı Eğitim; Ladson-Billings'in kültürel değerlere duyarlı pedagoji (KDDP) olarak tanımladığı ve 1990'lı yıllardan bu yana süregelen (1990; 1991; 1992a; 1992b; 1992c; 1994; 1995a; 1995b; 1998; 2005; 2006; 2009; 2014) çalışmalarına, Geneva Gay'in 
kültürel değerlere duyarlı öğretim (KDDÖ) olarak tanımladığı (1988; 1994; 1997; 2002a; 2002b; 2009; 2010; 2013; 2014; 2018) araştırmalarına, Django Paris ve H. Samy Alim'in (2012;2017) Culturally Sustaining Pedagogy olarak tanımladığı, eğitim sistemlerinde kültürel değerlerin korunması ve farklı kültürlerin eğitim sistemi aracılığıyla sürdürülmesi gerektiğini vurgulayan tartışmalarına, Kathryn Au (1980) ve Michele Foster (1995) gibi araştırmacıların kültür ve eğitimle ilgili antropolojik araştırmalarına, Kathryn Au'nun (2007) Culturally Responsive Instruction olarak tanımladığı ve bu yaklaşımı okuryazarlık (kültürel olarak farklı öğrencilerin) eğitiminde etkili bir yöntem olarak değerlendirdiği çalışmalarına (Keehne, Sarsona, Kawakami ve Au, 2018) dayalı olmakla birlikte, James ve Cherry Banks (2010), Sleeter ve Grant (1994) ve Sonia Nieto (2002) gibi çokkültürlü eğitim çalışmaları yürüten araştırmacıların, eleştirel pedagoji temsilcilerinden Freire (1991), Giroux (1984), Illich (2013) ve McLaren'in (1989) fikirlerine ve yapılandırmacı anlayışa (Villegas ve Lucas, 2002) dayalıdır (Şekil 1).

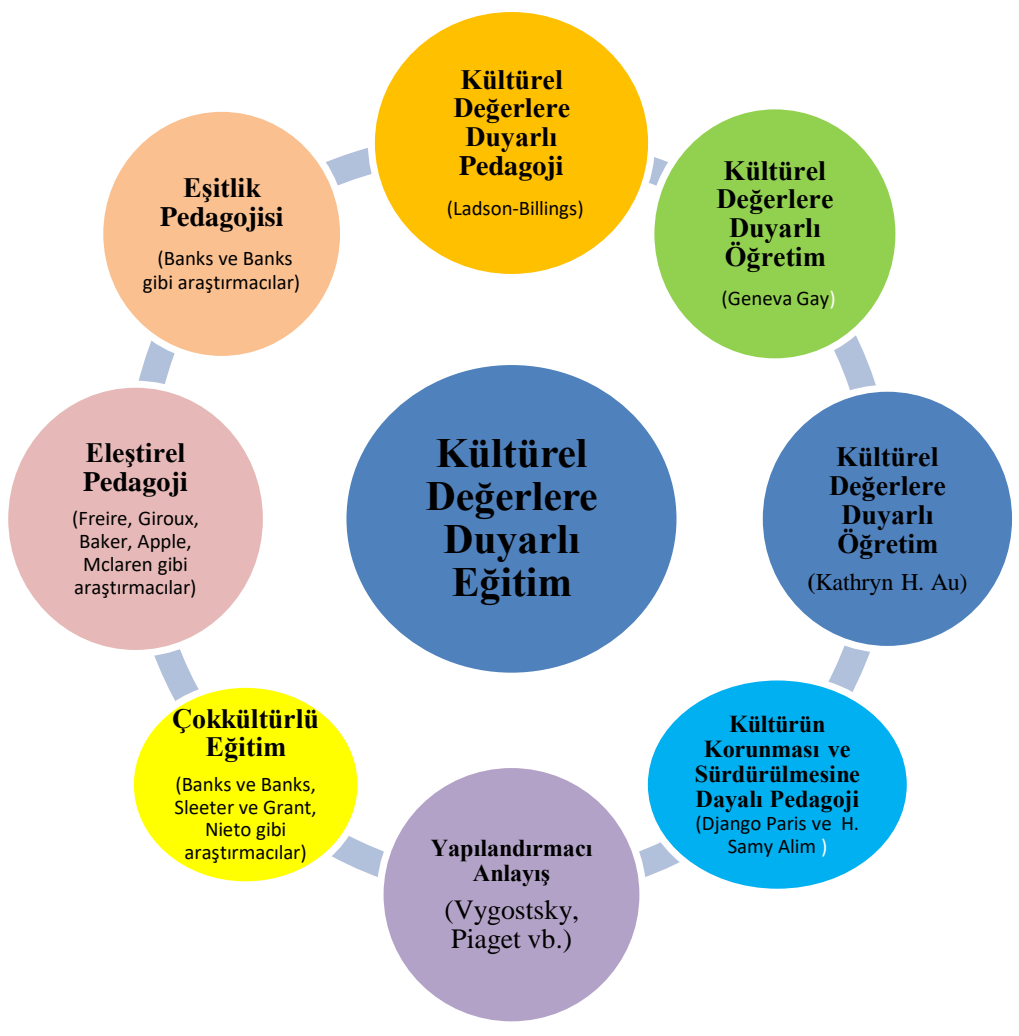


Şekil 1. Kültürel Değerlere Duyarlı Eğitim'in dayalı olduğu anlayışlar

\section{Kültürel Değerlere Duyarlı Ö̆̆gretim nedir?}

\section{Kültürel Değerlere Duyarlı Öğretim-KDDÖ (Culturally Responsive Teaching)}

KDDÖ, akademik açıdan akranlarına göre başarısız olan farklı kültürel değerlere veya engellilik gibi farklılıklara sahip öğrencilerin eğitsel, kişisel, sosyal, duygusal ve mesleki anlamda ihtiyaçlarını karşılamaya yönelik etkili pedagojik paradigmalardan biridir (Gay, 2002a; 2002b; 2018). Bu paradigmaya uygun olarak KDDÖ; öğrencilerin kültürel değerlerini, bilgilerini, önceki deneyimlerini, kültürel referans çerçevelerini, kültürel sermayelerini, altyapılarını, tutum, davranış ve bakış açılarını dikkate alarak, öğretimi öğrencilerin kültürel değerleriyle daha uyumlu/ilişkili hale getirmek ve böylece hem etkili bir öğretim yapmak hem de öğrenme süreçlerini öğrenciler için daha anlamlı hale getirmek şeklinde tanımlanabilir.

KDDÖ, farklılıklara sahip öğrencilerin kültürel bütünlüğünü koruyarak, bireysel yeteneklerini ve akademik başarılarını geliştirmelerini ve aynı zamanda öğrencilerin özgür, demokratik ve eleştirel bilince sahip olmalarını amaçlar. Bu anlayışta; kültürel ve engellilik dahil farklılıklara değer vermek, farklı bireylerden oluşan demokratik öğrenme toplulukları oluşturmak, farklı etnik kimliğe, dile ve kültüre sahip grupların, ailelerin ve öğrencilerin kültürel bilgilerini, yaşantılarını ve bilişsel şemalarını dikkate alarak çokkültürlü plan ve program geliştirmek, sınıf ortamı oluşturmak, öğretim yöntem, teknik ve stratejileri kullanmak büyük önem taşımaktadır. Bu şekilde eğitimde eşitsizlikle, toplumda kültürel önyargılarla, 1rkç1lıkla, hoşgörüsüzlük, adaletsizlik ve diğer istenmeyen durumlarla eğitim sayesinde mücadele edilebileceğine ve toplumsal adaletin yeniden inşa edilebileceğine, KDDÖ ile akademik başarının yanında, öğrencilerde aynı zamanda toplumsal bilincin ve sosyokültürel eleştirel bilincin de gelişeceğine inanılmaktadır (Gay, 2018).

\section{Kültürel Değerlere Duyarlı Öğretim'in Temel Unsurları}


KDDÖ'nün beş temel unsuru bulunmaktadır. Bunlar (Gay, 2018):

- Kültürel farklılıklar hakkında bilgi

Öğretmenler, belirli grupların kültürel özellikleri hakkında bilgi edinmelidir. Örneğin, öğretmenler farklı etnik grupların bilim, teknoloji, tıp, matematik, teoloji, ekoloji, barış, hukuk ve ekonomi alanlarında çok önemli katkılarından yeterince haberdar değillerdir. Çünkü farklılıklar hakkında bildiklerini düşündükleri şey, genellikle popüler kültür, kitle iletişim araçları, medya vb. tarafından iletilen yüzeysel veya çarpıtılmış bilgilere dayanmaktadır.

\section{- Programlara kültürel farklılıkların dâhil edilmesi}

Etnik ve kültürel farklılıklar hakkında bilgi birikimi elde etmenin yanı sıra öğretmenler, kültürel farklılıklarla ilgili bilgiyi programlara, materyallere, kitaplara ve içeriğe nasıl entegre edeceklerini öğrenmelidirler. Çünkü kültürel değerlere duyarlı öğretmenler, program tasarımlarının ve öğretim materyalinin çokkültürlü güçlü ve zayıf yanlarını nasıl belirleyeceklerini ve gerekli değişiklikleri nasıl yapacaklarını bilmelidirler.

- Kültürel hassasiyetin sergilenmesi ve işbirlikli ögrrenme topluluklarının oluşturulması

KDDÖ için hazırlığın üçüncü bir kritik bileşeni, kültürel açıdan farklı öğrenciler için öğrenmeye elverişli sınıf iklimlerini yaratmaktır. Öğretmenler, kültürel olarak farklı öğrencilerin kültürel altyapılarını, şemalarını ve önceki öğrenmelerini nasıl kullanacaklarını bilmelidirler. Öğretmenler, öğrencilerin potansiyellerine gerçekten inanmalı ve kültürel kimliklerini göz ardı etmemeli, aşağılamamalı veya ihmal etmemelidirler. $\mathrm{Bu}$ nedenle öğretmenler, kültürel değerlere duyarlı olmakla birlikte akademik başarı sağlamak için farklı öğrenciler arasında işbirlikli öğrenme gibi yaratıcı stratejiler kullanmalıdırlar.

- Kültürler Arası İletişim/Etkileşim 
Kültürel olarak farklı öğrencilerin neler bildikleri ve neler yapabileceklerini belirlemenin yanı sıra, yapabilecekleri şeyleri ortaya çıkarmak öğretmenlerin onlarla ne kadar iyi iletişim kurabildiklerine bağlıdır. Çünkü kültürel olarak farklı öğrencilerin iletişim kodları ve özellikle dilleri farklıdır. Öğretmenlerin, farklı öğrencileri daha etkili bir şekilde eğitmek için bu kodları çözmeleri gerekmektedir. Öğretmenler, farklı kültürel değerlerin veya farklılıkların öğrencilerin iletişim tarzlarını ve öğrenme davranışlarını nasıl şekillendirdiğini bilmelidirler (Gay, 2018).

-Öğretimin kültürel farklılıklara duyarlı olarak düzenlenmesi

KDDÖ'de amaç tüm öğrencileri sürece aktif biçimde katmaktır ve KDDÖ öğretimin temelde öğretmen merkezli olmasına karşıdır. Öğretmenin rollerini, yalnızca bilgi aktarıcısı olarak tanımlayan anlayıştan ziyade, öğrencilerin bilgi üretme ve edinme konusunda aktif katılımcı olmalarına yardım etme olarak tanımlar. Bu anlayış, öğretmenlerin, kültürel olarak farklı öğrencilerin sınıflara getirdiği kavramsal ve kültürel kaynakları veya değerleri kabul etmelerini gerektirir. Bu olmaksızın, öğretmenler öğrencilerin öğrenme ortamlarına getirdiği bilgi ve deneyimleri kullanamazlar (Gay, 2018).

\section{Kültürel Değerlere Duyarlı Pedagoji nedir?}

\section{Kültürel Değerlere Duyarlı Pedagoji- KDDP (Culturally Relevant Pedagogy)}

KDDP, Ladson-Billings'in 1990'lı yılların başından itibaren araştırmalarında incelemeye başladığı, kökeni Afrika'daki herhangi bir siyahî nüfusa dayanan Afrikal1-Amerikan öğrencileri kişisel, sosyal, duygusal ve akademik açıdan başarılı bir şekilde yetiştirebilen öğretmenlerin tutum ve davranışlarına, öğretim yöntemlerine, okul içi ve okul dışı etkinliklerine dayanmakla birlikte öğrencilerin ev kültürleri, kültürel değerleri, farklılıkları ve okul kültürleri arasında kültürel bir uyum yaratan daha önceki antropolojik araştırmalar üzerine de kuruludur. KDDP, 
öğrencilerin bilgi, beceri ve tutumlarını etkileyen kültürel değerleri ve referansları dikkate alarak öğrencileri entelektüel, sosyal, duygusal, eleştirel ve demokratik açıdan yetiştirmeyi amaçlayan bir pedagojidir. Bu pedagoji, öğrencilerin kültürel değerlerinden ve kültürel farklılıklarından hareketle, dünyayı anlamalarına ve anlamlandırmalarına yardımcı olur. KDDP, sadece akademik başarıyı değil aynı zamanda sosyal ve kültürel anlamda yetkinliği ve eleştirel bakış açısını da geliştirmeyi de amaçlar. Ladson-Billings'e (1995a; 1995b) göre, bütün farklılıklarına ve dezavantajlarına rağmen tüm öğrenciler; a) akademik açıdan başarılı olmalı, b) kültürel açıdan yetkinlik kazanmalı ve c) eleştirel sosyokültürel bilince sahip olacak şekilde yetiştirilmelidir (Şekil 2).

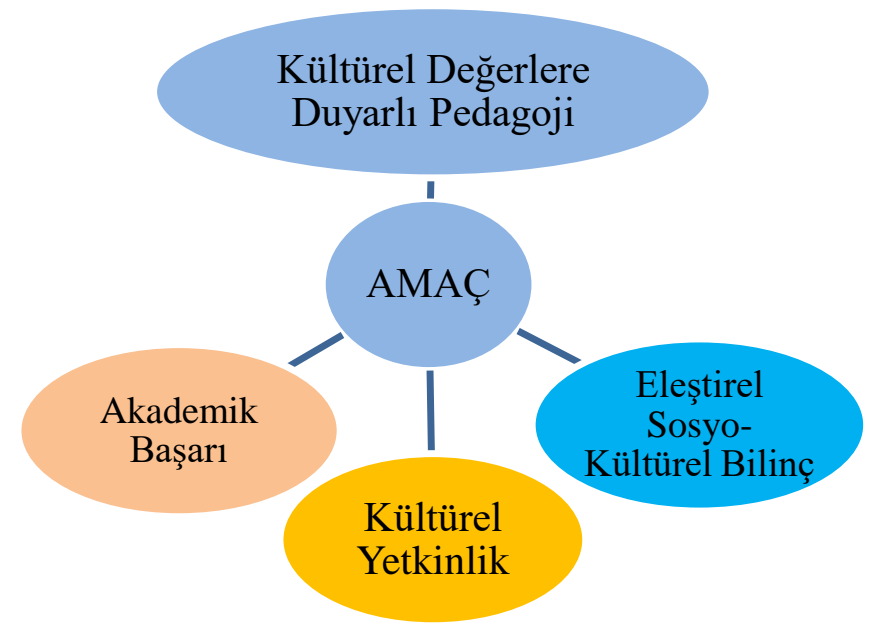

Şekil 2. Kültürel Değerlere Duyarlı Pedagoji'nin Amaçları

Bu yaklaşım sayesinde öğrenciler akademik başarının yanında eleştirel bir bakış açısıyla eğitim süreçlerini, toplumsal sorunları, sosyal adalet, eşitsizlik, ötekileştirme ve ayrımcılık gibi konuları inceleyebilecek, kendi kültürlerini korurken başka kültürleri de öğrenerek bu kültürel farklılıklara değer verecek ve aynı zaman da kültürel değerleri ve toplumu eleştirel süzgeçlerden geçirerek hem kendi kültürlerinde hem da başka kültürlerde yer alan dogmatik/yanlış değerlerle mücadele edecek ve demokratik, çokkültürlü bir toplum 
oluşturmada kendi rollerini sorgulayabileceklerdir. Dolayısıyla KDDP'nin üç temel amacı bulunmaktadir:

-Akademik Başarı: Bütün dezavantajlarına ve farklılıklarına rağmen tüm öğrenciler, akademik başarıyı deneyimlemelidir:

Her ne kadar akademik başarı ifadesi daha sonra Ladson-Billings (2014) tarafından ögrenci ögrenmeleri olarak değiştirilse de, KDDP anlayışına göre; toplumlarda, okullarda veya sınıflarda görülebilen mevcut eşitsizliklere ve kültürel olarak farklılıklara rağmen tüm öğrenciler okuma, yazma ve hesaplama gibi temel; teknolojik, sosyal ve politik gibi üst düzey becerileri geliştirebilmelidir. $\mathrm{Bu}$ pedagojiye göre, öğrencilerin başarısız olmalarının sebeplerinden biri maalesef öğretmenler arasında özellikle de kültürel olarak farklı ögrencilerin zaten başarısız olacaklarına dair inançtır. Bir diğer sebep de eğitimcilerin geleneksel olarak eğitimi kültüre entegre etmek yerine, baskın kültürü eğitime entegre etmeleri ve öğrencilerin kültürel altyapılarını dikkate almak yerine göz ardı etmeleridir. Oysa KDDP ile öğretmenler, öğrencilerin kültürlerini bir başarı aracı olarak görürler ve tüm öğrencilere akademik başarıyı tattırırlar. KDDP'de öğretmenler standartların kazandırılmasında ve karmaşık durumların üstesinden gelinmesinde öğrencilerin dillerinden/kültürlerinden örnekleri eğitim-öğretim ortamında kullanmalıdırlar. Bu şekilde öğrencilerin, hem okulda hem de gerçek yaşamda daha başarılı olmaları için öğretmenler çok değerli bir katkıda bulunmuş olacaktır (Ladson-Billings, 1995a; 1995b).

• Kültürel Yetkinlik: Öğrenciler, kültürel becerilerini kendi kültürel değerleri ile ilişkili olarak geliştirmelidir. Öğrenciler hem kendi kültürel değerleriyle hem de eğitim ortamlarında bulunan diğer kişilerin kültürel değerleriyle bağlantılar kurarak kültürel yetkinlik kazanırlar. 
Eğitim ortamları öğrencilerin kendileri gibi hissedebildikleri yerler olmalıdır. KDDP'ye göre öğrencilere, akademik olarak başarılı olmalarının yanında kendi kültürel değerlerini korumanın ve yeni kültürleri öğrenmelerinin de yolları öğretilmelidir (Ladson-Billings, 1995a; 1995b). KDDP ile öğrenciler hem kendi kültürel değerleriyle hem de eğitim ortamlarında bulunan diğer kişilerin kültürel değerleriyle bağlantılar kurarak kültürel yetkinlik kazanırlar. Kültürel becerilerin geliştirilmesine odaklanan öğretmenler, öğrencilerini kendi kültürel değerlerini eğitim ortamlarına entegre etmeleri için cesaretlendirirler. Kültürel yetkinliği geliştirmenin başka bir yolu ise aileleri ve/veya ebeveynleri eğitim öğretim ortamlarına katarak bu kişilerin çeşitli yeteneklerinden ve kültürel değerlerinden faydalanmaktır. Bu şekilde öğretmenler, belirli konularda öğrencilerin daha fazla araştırma yapması ve öğrenmesi için öğrencilerin yaşamlarında yer alan ve tanıdık oldukları kültürde yer alan bireylerin deneyimlerinden faydalanırken, öğrenciler de bu şekilde birbirlerinden farklı kültüre sahip bireyleri tanımış olurlar.

• Eleştirel Sosyokültürel Bilinç: Öğrenciler, toplumsal anlamda eşitsizlik, sosyal adalet, sömürge, güç, imtiyaz vb. durumlara ve kültürel anlamda da hem kendi kültürlerinde hem de başka kültürlerde yer alan dogmatik düşüncelere, yanlış kültürel değerlere karş1 eleştirel bilinç kazanmalıdır:

Öğretmenler, öğrencilere mevcut sosyal eşitsizlikleri tanımalarında, anlamalarında ve kendi kültürlerinde yer alan yanlışları da fark edip eleştirebilmelerinde yardımcı olmalıdır. KDDP'ye göre okullar, öğrencileri topluma ve kültürlere eleştirel bir gözle bakan bireyler olarak yetiştirmelidir. Öğrenciler, sosyal eşitsizlikleri, kültürel normları, eleştirel bir bakış açısıyla inceleyebilecek şekilde sosyokültürel açıdan eleştirel bir bilinç geliştirmelidir. Mevcut eğitim sistemlerinin, eğitim programlarının, öğretim materyallerinin içeriğine sıkı sıkıya bağlanmak yerine, sınıf ortamında bulunan öğrencilerin ön bilgilerini, yaşam deneyimlerini, 
kültürel değerlerini göz ardı etmek yerine, KDDP ile öğretmenler öğrencilerin kültürel değerlerinden hareketle eleştirel ve çokkültürlü bir bakış açısıyla sosyal adaleti yeniden inşa edecek öğrencileri yetiştirmelidir. Kısaca bu pedagoji, öğrencilerin mevcut kültürel değerleri ve toplumsal eşitsizlikleri tanıması, anlaması ve eleştirmesi için öğrencilerde eleştirel sosyokültürel bir bilinç geliştirmeyi de hedeflemektedir (Ladson-Billings, 1995a; 1995b).

\section{Kültürel Değerlere Duyarlı Pedagoji'nin Temel Prensipleri}

Ladson-Billings'in çalışmaları doğrultusunda KDDP'nin önemle üzerinde durduğu ilkeler şu şekildedir (Şekil 3):

Üst Düzey Beklenti (Communication of High Expectation): Hem öğretmenlerde hem de öğrencilerde herkesin üst düzey becerileri kazanabileceğine ve başarılı olabileceğine yönelik ortak bir anlayış oluşturulmalı ve bu yönde tutum ve işbirliği sergilenmelidir.

Aktif Öğretim Yöntemlerinin Kullanımı (Use Active Teaching Methods): Öğretim etkinlikleri, öğretim plan ve programları ögrencilerin yaparak yaşayarak öğrenebilecekleri ve öğrenmelerinde aktif bir rol ve sorumluluk alabileceği şekilde düzenlenir.

Kolaylaştırıcı/Danışman Rolünde Öğretmen (Facilitate Learning): Aktif bir öğrenme ortamında öğretmenlerin rolü rehberlik yapmaktır, öğrencilerin danışmanı rolünde ve kolaylaştırıcı olarak görev yapar. Ayrıca öğretmen, öğrencileriyle birlikte öğrenir.

Farklı Kültürel Değerlere Sahip Ebeveynlere ve Ailelere Yönelik Pozitif Bakış Açısı (Have Positive Perspectives on Parents and Families of Culturally and Linguistically Diverse Students): Öğrenciler hangi kültürden gelmiş olursa olsun ve hangi kültürel değerlere sahip olursa olsun öğretmenler, öğrencilere ve öğrencilerin ailelerine yönelik olumlu bir bakış açısına sahip olmalı ve gerektiğinde ebeveynleri ve aileleri öğrenme ortamlarına getirerek ebeveynlerin kültüre dayalı tecrübe ve becerilerini sınıf ortamında paylaşmalarını sağlamalıdır. Bu şekilde okullarda veli/aile/ebeveyn katılımı arttırılabilir. 
Kültürel Duyarlılı̆̆ Sergilemek (Demonstrate Cultural Sensitivity):Öğretmenler, sadece öğrencilerin kültürlerini öğrenmek ve kültürlerine saygı duymakla kalmamalı aynı zamanda bu değerleri öğretim etkinlikleriyle bütünleştirmeli ve sınıfta kullanmalıdır. Öğrenciler bu şekilde bir olayı veya eylemi yorumlamak için birden fazla yol ve bakış açısı olduğunu anlayabilir.

Öğretim Plan ve Programlarının Yeniden Düzenlenmesi (Reshape The Curriculum): Öğretim plan ve programları öğrencilerin kültürel değerleriyle, kültüre dayalı ön öğrenmeleriyle ve öğrencilerin ilgi ve ihtiyaçlarıyla uyumlu olarak basmakalıp ve ötekileştirici düşüncelerden, metinlerden arındırılarak yeniden şekillendirilmeli veya revize edilmelidir.

Kültürel Değerlere Duyarlı Öğretim (Provide Culturally Mediated Instruction): KDD öğretim ve öğrenme, öğrencilerin çokkültürlü bakış açısını teşvik eden bir ortamda gerçekleşmeli ve öğrencilerin kültürleriyle ilgili bilginin sürece dahil edilmesine izin vermelidir.

Öğrenci Kontrollü Sınıf Tartışmaları (Promote Student Controlled Classroom Discourse): Öğrencilere dersin bir kısmını kontrol etme, sınıfta kendi kültürel değerleri hakkında konuşma fırsatı verilmelidir. Bu durum öğretmenlerde ve sınıfın geri kalanında öğrencilerin kültürleriyle ilgili fikir oluşmasını sağlar.

Küçük Gruplarla Öğretim ve İşbirlikli Öğrenme (Include Small Group Instruction and Cooperative Learning): Öğretim, akademik dilin gelişimine katkıda bulunacak şekilde öğrencileri baskı altında tutmadan öğrenci kontrolünde bulunan ve birbirinden farklı kültürel değerlere sahip öğrenciler arasında rekabetten ziyade işbirlikli öğrenme gruplarıyla düzenlenmelidir. $\mathrm{Bu}$ şekilde, öğrenciler birbirlerinden farklı olsalar da, birbirlerinin öğrenmelerinden sorumlu olur ve aralarında olumlu bağlılık geliştirilerek ortak bir amaç doğrultusunda hareket ederler. 


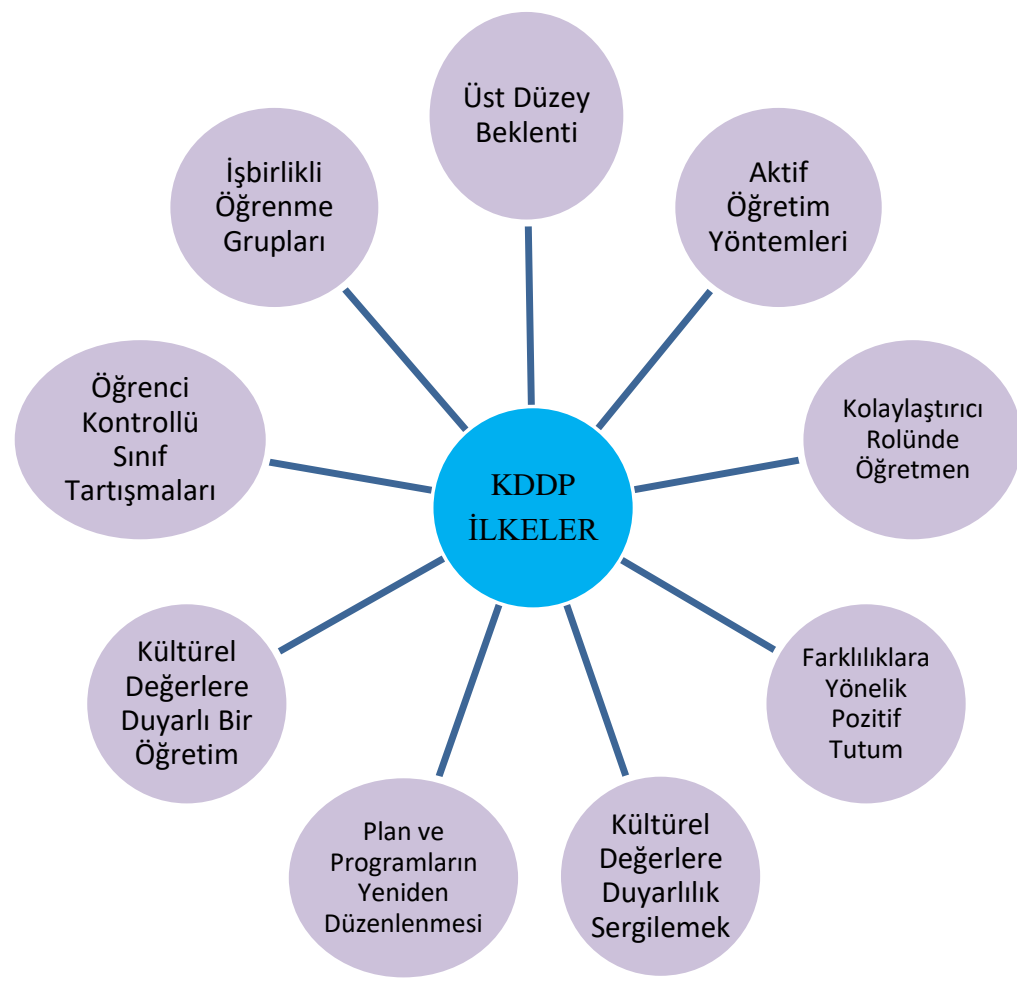

Şekil 3. Kültürel Değerlere Duyarlı Pedagoji'nin Temel Prensipleri

\section{Kültürel Değerlere Duyarlı Ĕ̆itim ile Çokkültürrlü Ĕ̆itim, Eleştirel Pedagoji ve}

\section{Eşitlik Pedagojisi arasında nasıl bir ilişki vardır?}

KDDE ile çokkültürlü eğitim (ÇE), birbiriyle yakından ilişkilidir. Çünkü hem KDDE hem de ÇE, öğrencilerin engellilik, dil, etnik köken ve sosyoekonomik düzey vb. farklılıklarına bakılmaksızın tüm öğrenciler için eşit ve adil bir eğitim anlayışını benimser. Her iki anlayış da eğitimde, kültürel farklılıkları reddetmek yerine dikkate alan ve farklılıkları dışlamak yerine farklılıklara değer veren bir anlayışı savunur. KDDE ve ÇE arasında birçok benzerlik olsa da ÇE; müfredatları, plan ve programları, eğitim kurumlarını yeniden yapılandırarak kültürel olarak farklı öğrencilere eşit eğitim fırsatları sağlayacak bir eğitim reformu hareketi olarak tanımlanırken, KDDE; kültürel değerlere duyarlı farklı öğretim teknikleriyle, kültürel olarak farklı öğrenciler arasında işbirlikli öğrenme gruplarıyla, sınıf ortamlarıyla, öğretmen tutum ve 
davranışlarıyla, veli/ebeveyn katılımlarıyla kültürel farklılıkları benimser ve kabul eder. Dolayısıyla KDDE, çokkültürlülük idealinin sınıf ortamına pratikte yansımasıdır.

KDDE, eşitlik pedagojisi ve eleştirel pedagoji arasında da benzerlikler son derece fazladır. Eşitlik pedagojisi; farklı gruplardan öğrencilere adil, insancıl ve demokratik bir toplum içinde etkili bir birey olmak için gerekli bilgi, beceri ve tutumları kazandırmak amacıyla etkili ve farklı öğretim stratejileri kullanmak ve buna uygun sınıf ortamları hazırlamak olarak tanımlanır (Banks ve Banks, 1995). KDDE, eleştirel pedagojinin de değindiği gibi; eşitsizliği teşvik eden mevcut okul yapılarının gözden geçirilerek yeniden adil bir eğitim sistemi inşa edecek şekilde düzenlenmesi gerektiğini önerir. Çünkü eğitim; 1rkçılık, cinsiyet ayrımı ve eşitsizlikle dolu sosyal ve politik bir bağlam içerisinde gerçekleşemez (Giroux, 1984). Yine eleştirel pedagojinin önemli temsilcilerinden biri olan McLaren'e (1989) göre, eğitim sistemi bilginin oluşturulduğu yerler olmalıdır. Eğitim sistemlerinde öğrenciler adalet, eşitlik vb. konularda sosyal dönüşümü sağlayacak ve eleştirel bilince sahip bireyler olacak şekilde yetiştirilmelidir. Benzer şekilde her üç anlayış da, öğretmenleri bilginin tek sahibi ve öğrencileri doldurulacak boş kaplar olarak görmek (Freire, 1991) yerine, öğrenme sürecini kolaylaştıran rehber olarak (Gay, 2002a; Ladson-Billings, 2009; Banks ve Banks, 1995) görür.

\section{Kültürel Değerlere Duyarlı Ö̆gretmen ne demektir, yeterlikleri nelerdir ve Türkiye'de öğretmen yeterlikleri ile klyaslandı̆̆ında benzerlik ve farklılıklar nelerdir?}

\section{Kültürel Değerlere Duyarlı Öğretmen}

KDDE açısından bakıldığında öğretmenler, kültürel değerlere duyarlı öğretmen ve geleneksel öğretmen olmak üzere sınıflandırılabilir. KDDE'yi benimseyen öğretmenleri geleneksel öğretmenlerden ayıran belirgin özellikler Tablo 2'de görüldüğü gibi ben ve öteki algısı, kişilerarası-sosyal ilişkiler ve bilgiye bakış açısı şeklinde üç tema altında toplanabilir (Ladson-Billings, 1990). 
Tablo 2. Kültürel değerlere duyarlı öğretmenleri geleneksel öğretmenlerden ayıran belirgin özellikler

\begin{tabular}{|c|c|c|}
\hline & Kültürel Değerlere Duyarlı Öğretmen & Geleneksel Öğretmen \\
\hline \multirow{5}{*}{ 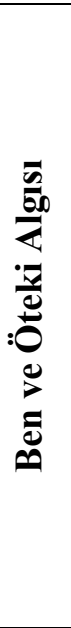 } & $\begin{array}{l}\text { Öğretimi bir sanat ve kendini bir sanatçı olarak } \\
\text { görür. }\end{array}$ & $\begin{array}{l}\text { Öğretimi teknik bir çalışma ve kendini bir } \\
\text { teknisyen olarak görür. }\end{array}$ \\
\hline & $\begin{array}{l}\text { Kendini toplumun bir parçası ve öğretimi } \\
\text { topluma bir şeyler katmak olarak görür }\end{array}$ & $\begin{array}{l}\text { Kendini toplumdan ayrı biri olarak görür } \\
\text { ve başarıy toplumdan kaçışın veya } \\
\text { gücün bir aracı olarak görür. }\end{array}$ \\
\hline & $\begin{array}{l}\text { Tüm öğrencilerin başarabileceğini düşünür ve } \\
\text { öğretimi buna inanarak yapar. }\end{array}$ & $\begin{array}{l}\text { Başarısızlığı, bazı öğrenciler için } \\
\text { kaçınılmaz olarak görür. }\end{array}$ \\
\hline & $\begin{array}{l}\text { Öğrencilerin kendi kültürel kimlikleriyle } \\
\text { toplumda var olabilmeleri için uğraşır ve } \\
\text { kültürel açıdan sınıfı heterojen olarak görür. }\end{array}$ & $\begin{array}{l}\text { Öğrencilerin tek bir kimlikle ve } \\
\text { genellikle baskın/egemen kültürel } \\
\text { kimlikle var olması için uğraşır ve sınıfı } \\
\text { homojen olarak görür. }\end{array}$ \\
\hline & $\begin{array}{l}\text { Öğretimi, öğrencilerin bilgilerini ve } \\
\text { potansiyellerini ortaya çıkarmak için bir araç } \\
\text { olarak görür. }\end{array}$ & $\begin{array}{l}\text { Öğretimi, öğrenciye bilgi yüklemek ve } \\
\text { öğrencinin zihnini bilgiyle doldurmak } \\
\text { için bir araç olarak görür. }\end{array}$ \\
\hline \multirow{5}{*}{ 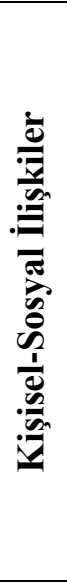 } & $\begin{array}{l}\text { Öğrenci-öğretmen ilişkilerinde insancıl anlayış, } \\
\text { iletişiminde ise-demokratik ilkeler vardır. }\end{array}$ & $\begin{array}{l}\text { Öğretmen öğrenci etkileşimi hiyerarşik, } \\
\text { otoriter ve katıdır. }\end{array}$ \\
\hline & $\begin{array}{l}\text { Öğretmen öğrenci iletişim etkileşim süreci } \\
\text { sadece sınıf veya okul ortamıyla sınırlı değildir. }\end{array}$ & $\begin{array}{l}\text { Öğretmen öğrenci iletişim ve etkileşim } \\
\text { süreci sadece sınıf veya okul ortamıyla } \\
\text { sinırlıdır. }\end{array}$ \\
\hline & $\begin{array}{l}\text { Tüm öğrencilerle iletişim halindedir. Ayrım } \\
\text { yapmaz. }\end{array}$ & $\begin{array}{l}\text { Sınırlı sayıda ve genellikle başarılı ya da } \\
\text { aynı kültüre sahip olduğu öğrencilerle } \\
\text { iletişim halindedir. }\end{array}$ \\
\hline & $\begin{array}{l}\text { Öncelikli olarak öğrenme topluluğu ve grupları } \\
\text { oluşturmaya çalışır }\end{array}$ & $\begin{array}{l}\text { Rekabetçi ve bireysel başarı anlayışııı ön } \\
\text { planda tutar. }\end{array}$ \\
\hline & $\begin{array}{l}\text { İşbirlikli öğrenmeyi teşvik eder. Öğrencileri } \\
\text { birbirlerinin öğrenmelerinden sorumlu tutar. }\end{array}$ & $\begin{array}{l}\text { Bireysel öğrenmelere, çalışmalara } \\
\text { yönlendirir. Her birey kendi öğrenme } \\
\text { sürecinden sorumludur. }\end{array}$ \\
\hline \multirow{5}{*}{ 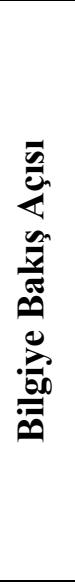 } & $\begin{array}{l}\text { Bilgi, öğretmen ve ögrenci tarafindan kültürel } \\
\text { çerçevede yeniden oluşturulur, dönüştürülür ve } \\
\text { yapılandırılır }\end{array}$ & $\begin{array}{l}\text { Bilgi değişmezdir, durağandır } \\
\text { öğretmenden öğrenciye aktarılır. }\end{array}$ \\
\hline & $\begin{array}{l}\text { Konular ve içerik, eleştirel olarak gözden } \\
\text { geçirilir. }\end{array}$ & $\begin{array}{l}\text { Konular ve içerik, olduğu gibi kabul } \\
\text { edilir. }\end{array}$ \\
\hline & $\begin{array}{l}\text { Öğrencilerin kültürel önbilgileriyle yeni } \\
\text { bilgileri arasında bağlantılar kurmasına } \\
\text { rehberlik eder. }\end{array}$ & $\begin{array}{l}\text { Öğrencinin önceki bilgilerini dikkate } \\
\text { almaz }\end{array}$ \\
\hline & $\begin{array}{l}\text { Öğrencilerin farklı kültürel değerlerini, bireysel } \\
\text { farklılıklarını ve kültürel altyapılarını dikkate } \\
\text { alır. }\end{array}$ & Öğrencilerin farklılıklarını göz ardı eder. \\
\hline & $\begin{array}{l}\text { Değerlendirme çok yönlüdür ve süreci de } \\
\text { kapsar. }\end{array}$ & $\begin{array}{l}\text { Değerlendirme tek yönlü ve sadece kağıt } \\
\text { kalem testlerine dayalıdır. }\end{array}$ \\
\hline
\end{tabular}

Kültürel değerlere duyarlı öğretmenler, kendileri ve öğrencileri hakkında olumlu bir algıya sahiptirler. Kültür, sosyoekonomik statü, engellilik ve dilin, eğitim ve okul başarısını nasıl etkilediğinin farkındadırlar. Bütün öğrencilere ilişkin ayrım gözetmeden yüksek 
beklentilere sahiptirler ve onlara bu beklentiyi bir şekilde hissettirirler. KDD öğretmenler, bir şekilde öğrencilerinin öğrencisi olmayı başararak, önce öğrencilerinin kültürlerini ve farklılıklarını anlarlar ve ardından öğrencilerden öğrendiklerini ders ve öğretim içeriğine dahil ederler. Çeşitli bağlamlarda öğrencilerin performanslarını değerlendiren farklı değerlendirme uygulamalarını geliştirmelerini sağlayacak iyi konu bilgisi ve pedagojik becerileri vardır (Dover, 2013; Gay, 2018; Ladson-Billings, 1995a; 1995b). Tüm kültürel farklılıkları kapsayıcı sınıflar ve sınıflarda işbirliğine dayalı öğrenme ortamları oluştururlar. Kültürel olarak farklılıklara sahip ebeveynleri, öğrencilerin eğitim süreçlerine ve okula dahil etmeye çalışırlar ve diğer öğretmenlerin farklılıklara yönelik varsa olumsuz tutumlarına karşı koyarak önyargılarla, ötekileştirmeyle mücadele ederler. (Gay, 2018; Ladson-Billings, 1995a; 1995b; Nieto, 2002).

\section{Türkiye'de Öğretmen Yeterlikleri ve Kültürel Değerlere Duyarlı Eğitim}

Türkiye'de Öğretmen Yetiştirme ve Ĕgitimi Genel Müdürlüğ̈̈ tarafindan Öğretmenlik Mesleği Genel Yeterlikleri belirlenmiştir. Bu çerçevede genel yeterlikler; 6 ana yeterlik, 31 alt yeterlik ve 233 performans göstergesi olarak belirlenmiştir (MEB, 2008). Ancak Aralık 2017 tarihinde yeniden bir güncelleme yapılarak Öğretmenlik Mesleği Genel Yeterlikleri; Mesleki Bilgi, Mesleki Beceri ve Tutum ve Değerler olmak üzere birbiriyle ilişkili ve birbirini tamamlayan 3 yeterlik alanı ile 11 alt yeterlik ve bu yeterliklere ilişkin 65 göstergeden oluşmaktadır (MEB, 2017b). Öğretmenlik mesleği genel yeterliklerinin, üniversitelerin ögretmen yetiştirmeye yönelik programlarında yer alan zorunlu ve seçmeli ders içeriklerinin belirlenmesinde, derslerde kullanılacak materyallerin tasarımında, öğrenme ortamlarının düzenlenmesinde yol gösterici olacă̆ düşünüldüğünden bu araştırma açısından da ayrı bir önem arz etmektedir. 
Kültürel değerlere duyarlı öğretmen yeterlikleri ile Türkiye'de Aralık 2017'de güncellenen Öğretmenlik Meslĕgi Genel Yeterlikleri (MEB, 2017b) araştırmacılar tarafından karşılaştırılarak KDDE anlayışı ile uyumlu olduğu düşünülen yeterlik göstergeleri belirlenmiştir: Her ögrenci öğrenebilir, ĕgitim-öğretim faaliyetlerinde aileyle işbirliği, ögrencilerin üst düzey bilişsel becerilerini geliştirici öğrenme ortamları (Ladson-Billings, 1995a; 1995b), demokratik öğrenme ortamları (Gay, 1994; Banks ve Banks, 2010) ve derslerini ögrrencilerin günlük yaşamlarıyla ilişkilendirme, öğrencilerin öğrenme süreçlerine aktif katılımlarını sağlama (Villegas ve Lucas, 2002) gibi yeterlik göstergeleri, kültürel değerlere duyarlı öğretmen yetiştirme anlayışına uygundur. Dolayısıyla Türkiye'de Aralık 2017'de güncellenen 65 yeterlik göstergesinden 29'unun kültürel değerlere duyarlı öğretmen yetiştirme anlayışıyla uyumlu olduğu söylenebilir.

\section{Tartışma ve Sonuç}

Türkiye'de güncellenen Ö̆gretmenlik Mesleği Genel Yeterlikleri (MEB, 2017b) dikkate alındığında, 65 yeterlik göstergesinden 29'u kültürel değerlere duyarlı öğretmen yetiştirme anlayışıyla uyumlu olduğundan, önceki (2008) Öğretmenlik Mesleği Genel Yeterliklerine oranla farklı kültürel değerlere duyarlılığın yeni öğretmen yetiştirme anlayışında daha fazla dikkate alınacağı söylenebilir. Ayrıca ve özellikle son yıllarda Türkiye'de uygulamaya konulan ve farklı kültürel değerlere sahip öğrencilerin talep etmeleri durumunda seçmeli olarak verilen bazı dillerde (Kurmançi, Zazaki, Arapça vb.) dersler/eğitim, üniversitelerde açılan Yaşayan Diller ve Lehçeler Enstitüleri ve araştırmacıların Türkiye'de çokkültürlü eğitim, kültürel değerlere duyarlı eğitim ile ilgili araştırmalara yönelmeleri ile Türkiye'de kültürel farklılıklara ilişkin Türkiye'nin kültürel zenginliğinin eğitim ortamlarına daha fazla yansıtılacağına dair daha olumlu bir anlayışın hakim olacağı varsayılabilir. Dolayısıyla bu alanda daha etkili çalışmaların yürütülmesi ile Türkiye'ye daha uygun bir anlayış geliştirilebilir. Çünkü eğitim 
sisteminde oluşturulacak hoşgörü ortamında farklılıklar ayrım olarak değil zenginlik olarak görüldügü taktirde daha da kenetlenmiş bir millet oluşturmak mümkündür (Memduhoğlu, 2008).

Türkiye'de öğrencilerin sahip olduğu etnik köken, dil, din, inanç gibi kültürel farklılıklar, eğitim sisteminde bulunan engelli öğrenci sayısı, mevcut durumda farklı okul ve kademelerde eğitim gören mülteci öğrenci sayısı ve eğitimde eşitsizlik raporları doğrultusunda Türkiye'de eğitim sisteminin daha kapsayıcı bir şekilde düzenlenmesi için KDDE anlayışının alternatif bir anlayış olarak değerlendirilmesinde faydalar olabilir. Ancak KDDE'nin amacı fark gözetmeksizin tüm öğrencileri akademik açıdan başarılı, kültürel açıdan yetkin ve sosyokültürel açıdan eleştirel, demokratik, barışçıl ve insan haklarına saygılı bireyler olarak yetiştirmek olduğundan bu anlayış Türkiye'de politik tartışmalara malzeme edilmemelidir.

Diğer taraftan KDDE, tüm eğitim-öğretim süreçlerini tamamen öğrencilerin kültürlerine göre düzenlemek anlamına gelmediği gibi, eğitim-öğretim süreçlerinde öğrencilerin kültürel değerlerini tamamen yok saymak veya göz ardı etmek anlamına da gelmemektedir. Çünkü öğrenciler eğitim sistemlerine birer boş levha olarak gelmezler. Her öğrenci okula geldiğinde, içinde yetiştiği aile, büyüdüğü çevre, dil, din, inanç, sosyal, ekonomik ve kültürel etmenler gibi farklı değerlerin etkisiyle oluşan farklı şemalara sahip olarak gelir. Buna kültürel referans çerçeveleri, önbilgiler, bilişsel şemalar veya kültür temelli bilgi diyebiliriz. Bununla birlikte okulda öğrencilerin öğrenecekleri bilgiler bulunmaktadır. Bu bilgiye de alan bilgisi, içerik bilgisi, konu bilgisi veya okul temelli bilgi diyebiliriz. İşte KDDE, her iki bilgi türünün kesiştiği noktada başlar (Şekil 4). Başka bir ifadeyle KDDE'de yeni bilgiler (okul temelli bilgi), önceki bilgiler (kültürel referans çerçeveleri) üzerine inşa edilir. 


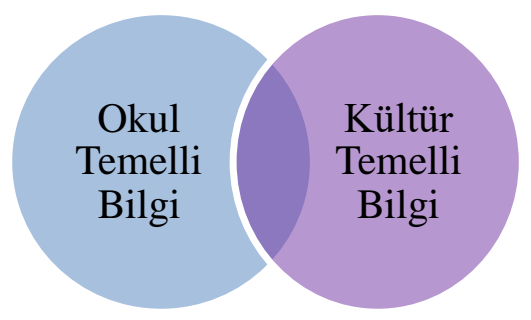

Şekil 4. Kültürel Değerlere Duyarlı Eğitim Açısından Bilgi

KDDE, ne tamamen kültüre göre yapılır ne de kültürel değerler tamamen göz ardı edilir. Kültürel değerlerden kaynaklı önceki bilgileri göz ardı etmek, çocukların bilgiyi yapılandırma sürecini reddetmektir. Öğrencilerde bilginin inşasını desteklemek için öğretmenler, öğrencilerin zaten bildikleri ile yeni fikir ve deneyimler arasında köprü kurmalarına yardımcı olmalıdır. Bu durum, öğrencilerin ilgisini çeken ve kendileri için anlamlı olan sorular veya konular bağlamında sorgulama, yorumlama ve analiz etme boyutlarını içerir. Öğrenciler, öğrenme için farklı bilgi çerçevelerine sahip olduklarından, belirli bir bilgiyi aynı şekilde oluşturmaları gerekmez. Kültürel çeşitliliğin, farklılıkların ve değerlerin öğrenmede merkezi bir rol oynadığını kabul eden yapılandırmacılık anlayışı da, yeni öğrenilen konuların öğrencilerin farklı kültürel geçmişlerine bağlı olduğunu destekler. Dolayısıyla kültürel referans çerçeveleri tamamen yok sayıldığında öğrencilerde anlamlı öğrenmeler gerçekleşmeyebilir ve akademik başarısızlık, öteki hissetme ve bunun sonucunda okulu terk etme gibi birçok olumsuz durumla karşıllaş1labilir.

Diğer taraftan sadece kültür temelli eğitim de bilimsel bilgiden uzaklaştırabilir ve kültür içerisinde yer alan yanlışlarla da mücadele edilemez. Kısaca söylemek gerekirse, KDDE yanlış da olsa kültürü savunmak ve kültürel değerleri olduğu gibi kabul etmek değildir. Çünkü KDDE'nin önemli amaçlarından biri de kültürlerde yer alan insanlık dışı, dogmatik yanlışlarla ve toplumda görülen her türlü eşitsizlikle, asimilasyonla, ötekileştirmeyle mücadele etmek ve öğrencilerde bu tür yanlışları fark edecek eleştirel sosyokültürel bilinç geliştirmek olduğundan KDDE, saf kültüre dayalı bir eğitim de değildir. 
Ancak bu durum sadece tek bir kültürün doğru olduğu ve tüm eğitim sisteminin tek bir grubun (hakim ya da baskın kültür) kültürel değerlerine uygun olarak düzenlenmesi ve bir ülkeyi oluşturan farklılıkların reddedilmesi anlamına da gelmemektedir. Aksine, KDDE'nin amaçlarından biri de öğrencilerde kendilerinden farklı kültürel değerlere sahip bireylerin olabileceği/olduğu ve tüm bireylerin tüm farkl1lıklarıyla birlikte ülkenin önemli bir değeri olduğu algısını geliştirmektir. Bu şekilde KDDE anlayışı ötekileştirme, ayrıştırmayla da mücadele etmeyi ve kültürel değerlerin korunup sürdürülmesini de amaçlar.

Bir örnek verecek olursak, KDDE anlayışı ülkede kullanılan resmi dilin kazandırılmasını amaçlarken, öğrencilerin evde konuştukları dillerinin de tamamen göz ardı edilmemesi gerektiğini savunur. Bilakis, tüm öğrenme-öğretme süreçlerinde gerektiğinde öğrencilerin dil gibi kültürel değerlerinden örnekler kullanılması gerektiğine vurgu yapar (Ladson-Billings, 1995b). Bu şekilde öğrenciler kendi kültürel referans çerçeveleriyle uyumlu öğrenmeler gerçekleştirirken aynı zamanda resmi dili de öğrenirler. Böylece hem kendini hem kültürünü (dilini) değerli bulur hem de eğitim-öğretim ortamlarına aidiyet duygusu gelişirken bir yandan da farklı dilleri (diğer farklı öğrencilerin), resmi dili ve kültürleri de öğrenmiş olur. Diğer taraftan farklı kültürlerden olan bireyler de daha küçük yaşlardan itibaren eğitim-öğretim ortamlarında farklı dilleri, inançları kısaca farklı kültürel değerleri olan bireylerin varlığını görür ve farklılıklara dair olumlu bir algı oluşur. Bunun sonucunda ülke içerisinde yer alan tüm kültürel farklılıklar eğitim sayesinde yaşatılır ve sürdürülürken, ülkenin kültürel çeşitliliği ve zenginliği hiç kimse ötekileştirilmeden eğitim aracılığıyla koruma altına alınmış olur (Paris, 2012). Dolayısıyla KDDE, sadece azınlıkta olan veya çoğunlukta olan, avantajlı veya dezavantajlı olan öğrencilere yönelik bir anlayış da değildir, herkese yöneliktir.

Diğer taraftan KDDE'de, yalnızca öğrencilerin kültürel geçmiş̧lerine ve tarihlerine saygı göstermekle kalmayıp aynı zamanda öğrencilerin yaşam deneyimlerinden ve öğrenme 
stillerinden yararlanacak öğretim stratejilerinin geliştirilmesi ve kullanılması da gerekmektedir. Bu durum öğretmenlerin hem öğretecekleri konuyu (konu alanı) iyi bir şekilde bilmelerini hem de öğrencilerini yakından tanımalarını (öğrencilerinin geçmiş yaşantılarını, kültürünü, kültürel değerlerini) onların yaşantılarının öğrenmeleri nasıl etkilediğini, kültüre özgü tutum ve davranışlarını, kültüre özgü öğrenme stillerini ve bunlara uygun öğretim ve değerlendirme stratejilerini (pedagoji) bilmelerini gerektirir.

Yine alan yazında fen bilimleri ve matematik dersleri branşında görevli öğretmenlerin diğer branşlara oranla KDDE'ye ilişkin daha düşük düzeyde olumlu düşünceye ve daha fazla kaygıya sahip olduğu belirtilmektedir (Kotluk, 2018). Benzer şekilde Brown (2017), öğretmenler arasında KDDE'nin fen ve matematik alanlarına uygun olmadığı yönünde yanlış bir algının olduğunu, çok sayıda öğretmenin konu içeriklerinin (özellikle matematik ve fen alanlarında) ve kültürel çeşitliliğin birbiriyle uyuşmadığını, konu içerikleri ile kültürü birleştirmenin mümkün olmadığını düşündüğünü belirtmektedir. Aslında bu bakış açısı doğru değildir ve bu durum, pek çok öğretmenin farklı kültürel gruplar hakkında yeterince bilgi sahibi olmamasından, kültürel değerlere duyarlı eğitim ve çok kültürlü eğitimden uzak oldukları gerçeğinden kaynaklanmaktadır. Diğer taraftan bu yanılgının oluşmasında fen ve matematik alanlarında yer alan konuların genellikle formüller içermesi, pozitivist bakış açısıyla deneysel neden ve sonuç ilişkilerine dayalı olması ve öğretmenlerin bilim ile kültürel farklılıkların birbirinden ayrı şeyler olduğunu düşünmeleri etkili olmuş olabilir (Kotluk, 2018). Oysa literatür incelendiğine kültürel değerlere duyarlı fen eğitimine (Tan, 2011; Mensah, 2011; Nam, Roehrig, Kern ve Reynolds, 2013; Brown, ve Crippen, 2016; 2017) ve matematik öğretimine yönelik (Aguirre ve Zavala, 2013) özellikle yurtdışı alan yazında fazla sayıda çalışma bulunmaktadır. Son zamanlarda kültürel değerlere duyarlı STEM eğitimi (Delaney, Lee ve Bos, 2017) araştırmaları da yapılmaktadır. Dolayısıyla KDDE, sadece sosyal bilimler alanında uygulanan bir anlayış değildir. 
Alan yazında KDDE, KDDÖ, KDDP ve ÇE kavramları, aralarında büyük benzerlikler olduğundan birbiri yerine kullanılmakla birlikte aslında tam anlamıla aynı anlama gelmemektedir. ÇE bir felsefi anlayış veya temele alınan bir eğitim ideolojisi ise, KDDE, bu eğitim felsefesinin eğitim-öğretim ortamlarına, süreçlerine, öğretmen davranışlarına, sınıf içi ve sınıf dışı uygulamalarda yansımasıdır. ÇE, eğitimin kültürel olarak farklı öğrencilere yönelik niçin yapılması gerektiğine daha çok değinirken, KDDE kültürel olarak farklı öğrencilere öğretimin nasıl yapılacağına odaklanır. Örneğin ÇE, herkesin eğitim hakkı olduğunu ve herkese eşit, adil bir eğitim verilmesi gerektiğini ilkesel olarak benimserken, KDDP (Gloria LadsonBilings) bu ilkenin sınıf içinde veya dışında öğretmen tutum ve davranışlarına pratikte nasıl yansıması gerektiğine, KDDÖ (Geneva Gay) ise yine aynı durumun plan, program ve öğretimyöntem tekniklerine nasıl yansıtılacağına vurgu yapar.

Kültürel farklılıklara rağmen öğrencilerin demokratik toplumun etkin birer üyesi olarak yetiştirilmesi, eleştirel sosyokültürel bilincin geliştirilmesi, tüm öğrencilerin başarılı olabileceğine inanılması, okullara gücün, sömürünün ve düzenin devamını sağlayan kurumlar olarak bakmak yerine sosyal adaleti sağlayacak kurumlar olarak bakılması gerektiği, eşitlik pedagojisinin, KDDE'nin ve eleştirel pedagojinin ortak yönleridir. Özetle, her üç yaklaşımda da öğretmenler, tüm öğrencilerin öğrenebileceğini ve bilginin yapılandırıcısı olduğunu varsayarlar. KDDE, sadece okul kültürünü öğrencilerin kültürüne uyarlamak değil aynı zamanda öğrencilerin kültürel değerlerini ve altyapılarını kullanarak, kendilerini ve başkalarını anlamalarını, sosyal etkileşimleri yapılandırmalarını ve bilgiyi kavramsallaştırmalarını amaçlayan bir eleştirel pedagoji anlayışıdır (Ladson-Billings, 1990; 1991; 1992c). İlk amacı, öğrencilerin eleştirel düşünmeyi öğrenmelerine yardımcı olmak yerine mevcut ekonomik ve sosyal düzenin devamı için ara elaman yetiştirme olan statükocu eğitim anlayışına karşıdır.

\section{Sonuç yerine;}


• KDDE'nin amacı tüm öğrencileri bütün farklılıklarına rağmen akademik açıdan başarılı, kültürel açıdan yetkin ve sosyokültürel açıdan eleştirel, demokratik, barışçıl ve insan haklarına saygılı bireyler olarak yetiştirmektir.

•KDDE, ne tüm eğitim-öğretim süreçlerini tamamen kültüre göre düzenlemektir ne de eğitim-öğretim süreçlerinde öğrencilerin kültürel değerlerini tamamen göz ardı etmektir.

- KDDE, dogmatik ve insanlık dışı da olsa kültürel değerleri veya mevcut sosyal düzeni olduğu gibi savunmak değildir.

-KDDE'nin amacı toplumu bölmek, kutuplaştırmak ya da ayrıştırmak anlamına da gelmemektedir. Aksine amaç; eğitim sistemi aracılığıyla tüm farklılıklarıyla birbirine saygı gösteren, birbirini kabul eden, değer veren, hiç kimsenin ötekileştirilmediği ve tüm kültürel farkl111kların/değerlerin korunduğu ve sürdürüldüğü bir toplum oluşturmaktır.

- KDDE, sadece azınlıkta olan veya çoğunlukta olan, avantajlı veya dezavantajlı olan öğrencilere yönelik bir anlayış da değildir, herkese yöneliktir.

- KDDE, sadece kültürel değerlere duyarlılık sergilemek veya farklılıklara sayg1 göstermek de değildir, aynı zamanda kültürel farklılıkların korunmasını ve kültürel çeşitliliğin eğitim aracılığıyla sürdürülmesini de amaçlar.

- KDDE, sadece sosyal bilimler alanında uygulanan bir anlayış değildir.

-KDD Eğitim, KDD Öğretim ve KDD Pedagoji ile Çokkültürlü Eğitim birbirlerine benzeseler de aynı şeyler değildir.

\section{Öneriler}

•Türkiye'nin kültürel zenginliği, barındırdığı kültürel farklılıklar, engelli öğrenci sayısı, eğitim sistemindeki mülteci-sığınmacı öğrenci sayısı ve eğitimde eşitsizlik raporları doğrultusunda Türkiye'de KDDE anlayışının detaylı, kapsamlı, deneysel ve teorik uygulamalarla alternatif bir anlayış olarak değerlendirilmesinde faydalar olabilir. 
- Eğitim politikacıları ve uygulayıcılarına; tüm farklılıkları daha iyi kapsayacak şekilde var olan sistemi revize etmeleri, evrensel değerleri daha fazla benimseyen bir anlayış için farklı kültürel değerlere sahip paydaşların da görüş ve talepleri alınarak eğitim politikalarını gözden geçirmeleri ve bu politikaları kararlı ve kapsayıcı bir şekilde zamana yayarak, sağlam bir alt yapı oluşturmaları önerilebilir.

•Üniversitelerde öğretmen eğitimi programlarına Türkiye'de kültürel farklılıklar, çokkültürlü eğitim, kültürel değerlere duyarl1; eğitim, öğretim, ölçme ve değerlendirme gibi derslerin daha fazla konulması önerilebilir.

-Diğer taraftan öğretmenlik mesleğinin ve yeterliklerinin dinamikliği göz önüne alınarak sadece aday öğretmenlerin değil görev başında olan öğretmenlerin de mesleki açıdan kendilerini geliştirebilecekleri, kültürel değerleri eğitim-öğretim sürecine daha iyi yansıtabilecekleri programlar da öğretmen eğitimcileri tarafından düzenlenmelidir. Yurtdış1 alan yazında öğretmenlere veya öğretmen adaylarına yönelik geliştirilen kültürel değerlere duyarlı öğretmen eğitim programlarının (intervention programs) öğretmenler üzerinde etkili olduğunu belirten çalışmalar mevcuttur (Ritosa, 2017). Dolayısıyla öğretmenlere yönelik kültürel değerlere duyarlı hizmet içi veya hizmet öncesi programların tasarlanması etkili olabilir.

- KDDE ile ilgili en büyük problemlerden biri de Türkçe alan yazın yetersizliğidir. Dolayısıyla, araştırmacıların, bu alana odaklanarak, öğretmenlerin, öğretmen eğitimcilerinin, yeni araştırmacıların veya öğrencilerin yararlanabileceği şekilde Türkçe yayınlar üretmeleri faydalı olacaktır. Özellikle, bu çalışmada değinilen kültürel değerlere duyarlı; eğitim, öğretim, pedagoji ve öğretmen yeterliği dışında kültürel değerlere duyarlı; sınıf yönetimi, okul, yönetim, ölçme değerlendirme vb. konularda doküman analizi yapılabilir.

\section{MAKALENIN BÍLIMDEKİ YERİ}


Eğitim Bilimleri, Eğitim Programları ve Öğretim

\section{MAKALENIN BILIMDEKİ ÖZGÜNLÜĞ̈̈}

Bu çalışmada alan yazına dayalı olarak elde edilen bilgiler, özellikle kültürel olarak farklı öğrencilerin eğitim-öğretim süreçlerinin daha etkili bir şekilde yürütülmesini hedefleyen ve herkes için eğitim, ĕgitimde firsat eşitliği ilkeleri doğrultusunda Türkiye eğitim sisteminde tüm bireyleri kapsamayı amaçlayan düzenlemelere katkı sunacaktır. Bu çalışma ile KDDE hakkında Türkiye'de henüz oluşturulmamış literatüre de katkı sağlanmıştır.

\section{KAYNAKÇA}

Aguirre, J. M., \& del Rosario Zavala, M. (2013). Making culturally responsive mathematics teaching explicit: A lesson analysis tool, Pedagogies: An international journal, 8(2), 163 190.

Aronson, B., \& Laughter, J. (2015). The theory and practice of culturally relevant education a synthesis of research across content areas. Review of Educational Research, 1-44.

Ataç, E. (2017). Türkiye'de eğitim eşitsizliğini okumak: İstatistikler ve coğrafi dağılımlar, Ĕgitim ve Bilim, 42, (192).

Au, K. H. (1980). Participation structures in a reading lesson with Hawaiian children: Analysis of a culturally appropriate instructional event. Anthropology \& Education Quarterly, 11 (2), 91-115.

Au, K. H. (2007). Culturally responsive instruction: Application to multiethnic classrooms. Pedagogies: An International Journal, 2(1), 1-18.

Aydın, H. (2013). Dünya'da ve Türkiye'de çokkültürlü eğitim tartışmaları ve uygulamaları. Ankara: Nobel Akademik Yayıncılık.

Banks, C. A. M \& Banks, J. A. (1995) Equity pedagogy: An essential component of multicultural education, Theory Into Practice, 34 (3), 152-158 
Banks, J. A., \& Banks, C. A. M. (Eds.). (2010). Multicultural education: Issues and perspectives (7th ed.). Hoboken, NJ: John Wiley.

Brown, J. C., \& Crippen, K. J. (2016). Designing for culturally responsive science education through professional development. International Journal of Science Education, 38(3), 470-492.

Brown, J. C. (2017). A metasynthesis of the complementarity of culturally responsive and inquiry-based science education in K-12 settings: Implications for advancing equitable science teaching and learning. Journal of Research in Science Teaching, 54(9), 11431173.

Brown, J. C., \& Crippen, K. J. (2017). The knowledge and practices of high school science teachers in pursuit of cultural responsiveness. Science Education, 101(1), 99-133.

Delaney, C.J., Lee, K.S. ve Bos, B. (2017). Evaluating Instruction for Culturally Responsive Teaching Using a STEM Curriculum Review Rubric. In P. Resta \& S. Smith (Eds.), Proceedings of Society for Information Technology \& Teacher Education International Conference (pp. 394-397). Austin, TX, United States: Association for the Advancement of Computing in Education (AACE). from https://www.learntechlib.org/p/177313/. adresinden erişildi.

Dover, A.,G. (2013). Teaching for social justice: from conceptual frameworks to classroom practices, Multicultural Perspectives, 15:1, 3-11

Eğitim Reformu Girişimi-ERG, (2017). Bir Arada Yaşamı ve Geleceği Kapsayıcı Eğitimle İnşa Etmek. $\quad$ https://indd.adobe.com/view/6066c857-843a-4d49-b7e9-77f635a950cf adresinden 12.12.2017 tarihinde erişildi.

Erdem, C. (2017). Sınıfında mülteci öğrenci bulunan sınıf öğretmenlerinin yaşadıkları öğretimsel sorunlar ve çözüme dair önerileri. Medeniyet Eğitim Araştırmaları Dergisi, 1(1), 26-42. 
Foster, M. (1995). African American teachers and culturally relevant pedagogy. In J. A. Banks \& C. A.M. Banks (Eds.), Handbook of research on multicultural education (pp . 570581). New York : Macmillan

Freire. P. (1991). Ezilenlerin pedagojisi. Çev: D. Hattatoğlu ve E.Özbek. İstanbul: Ayrıntı Yayınlar1.

Gay, G. (1988). Designing relevant curricula for diverse learners. Education and urban society, $20(4), 327-340$.

Gay, G. (1994). At the essence of learning: Multicultural education. [Çevrim-içi: https://files.eric.ed.gov/fulltext/ED386410.pdf], Erişim tarihi: 29 Ekim 2017.

Gay, G. (1997). The relationship between multicultural and democratic education. The Social Studies, 88(1), 5-11.

Gay, G. (2002a). Preparing for culturally responsive teaching. Journal of Teacher Education, 53(2), 106-116.

Gay, G. (2002b). Culturally responsive teaching in special education for ethnically diverse students: setting the stage. Qualitative studies in education, 6, 613-629

Gay, G. (2009). Similar concerns, different perspectives of social studies and multicultural education, Social Studies Review, 48(1), 25-27.

Gay, G. (2010). Acting on beliefs in teacher education for cultural diversity. Journal of Teacher Education, 61(1-2), 143-152.

Gay, G. (2013). Teaching to and through cultural diversity, Curriculum Inquiry, 43:1

Gay, G. (2014). Kültürel değerlere duyarlı eğitim: Teori, araştırma ve uygulama (2. Baskı). Hasan Aydın (Çev. Ed.). Ankara: Anı Yayıncılık.

Gay, G. (2018). Culturally responsive teaching: Theory, research, and practice. (3rd Ed.).Teachers College Press.

Giroux, H. A. (1984). Ideology, culture, and the process of schooling. Temple University Press. 
Hollins, E. (2011). Teacher preparation for quality teaching. Journal of Teacher Education, 62(4), 395-407

Illich, I.D. (2013). Okulsuz toplum (7.Baskı). İstanbul: Şule Yayınları.

Karataş, K. ve Oral, B. (2016). Kültürel değerlere duyarlı pedagoji. Akademik Sosyal Araştırmalar Dergisi, 4 (34), 431-447

Keehne, C. N., Sarsona, M. W., Kawakami, A. J., \& Au, K. H. (2018). Culturally Responsive Instruction and Literacy Learning. Journal of Literacy Research, 50(2), 141-166.

KONDA. (2006). Biz Kimiz? Toplumsal Yapı Araştırması. Konda Araştırma ve Danışmanlık.http://www.konda.com.tr/tr/raporlar/2006_09_KONDA_Toplumsal_Yapi. pdf

KONDA. (2007). Gündelik hayatta din, laiklik ve türban araştırması. http://www.konda.com.tr/tr/raporlar/2007_09_KONDA_Gundelik_Yasam.pdf

KONDA. (2011). Kürt meselesi'nde algı ve beklentiler. İstanbul: İletişim Yayınları.

Kotluk, N. ve Kocakaya, S. (2016). Culturally responsive/relevant pedagogy: Teachers' competencies, instruction and classroom management. 4.rd International Conference on Curriculum and Instruction: Curriculum Studies in Teacher Education, 27-30 October 2016, Antalya, Turkey.

Kotluk, N. ve Kocakaya, S. (2017a). A content analysis of graduate dissertations conducted in the field of multicultural education in Turkey (2001-2016). 26 $6^{\text {th }}$ International Congress on Educational Sciences (ICES), 20-23 April, 2017, Antalya, Turkey,

Kotluk, N., ve Kocakaya, S. (2017b). Teachers' culturally relevant teaching self-efficacy beliefs in Turkey: A scale development study. 2nd Eurasian Conference on Language and Social Sciences (ECLSS 2017), 29 September -October 1, 2017, Antalya, Turkey. 
YYÜ Eğitim Fakültesi Dergisi (YYU Journal of Education Faculty), 2018; 15(1):749-789, http://efdergi.yyu.edu.tr

Kotluk, N. (2018). Kültürel değerlere duyarlı eğitime ilişkin öğretmenlerin öz-yeterlik algılarının ve görüşlerinin incelenmesi. Yayımlanmamış doktora tezi. Yüzüncü Y1l Üniversitesi, Van.

Kultas, E. (2017). Türkiye' de Bulunan Ĕ̆itim Çağındaki Suriyeli Mültecilerin Ĕ̆itimi Sorunu (Van İli Örneği), Yayımlanmamış yüksek lisans tezi, Van.

Ladson-Billings, G. (1990). Like lightning in a bottle: Attempting to capture the pedagogical excellence of successful teachers of Black students. International Journal of Qualitative Studies in Education, 3,335-344.

Ladson-Billings, G. (1991). Beyond multicultural illiteracy. Journal of Negro Education, 60(2), $147-157$

Ladson-Billings, G. (1992a). Culturally relevant teaching: The key to making multicultural education work. In C.A. Grant(Ed.), Research and multicultural education (pp. 106-121). London: Falmer Press.

Ladson-Billings, G. (1992b). Liberatory consequences of Literacy: A case of culturally relevant instruction for African American students. Journal of Negro Education, 61, 378-391.

Ladson-Billings, G. (1992c) Reading between the lines and beyond the pages: A culturally relevant approach to literacy teaching. Theory into Practice, 31(4), 312-320

Ladson-Billings, G. (1995a). But that's just good teaching! The case for culturally relevant pedagogy. Theory into Practice, 34, 159-165

Ladson-Billings, G. (1995b). Toward a theory of culturally relevant pedagogy, American Educational Research Journal, 32(3), 465-491.

Ladson-Billings, G. (1998). Just what is critical race theory and what's it doing in a nice field like education? In E. Taylor, D. Gillborn, \& G. Ladson-Billings (Eds.), Foundations of critical race theory in education (pp. 17-36). Abingdon, NJ: Routledge.

Ladson-Billings, G. (2005). Is the team all right. Journal of Teacher Education, 56(3), 229-234. 
YYÜ Eğitim Fakültesi Dergisi (YYU Journal of Education Faculty), 2018; 15(1):749-789, http://efdergi.yyu.edu.tr

Ladson-Billings, G. (2006). From the achievement gap to the education debt: Understanding achievement in U.S. schools. Educational Researcher, 35(7), 3-12.

Ladson-Billings, G. (2009). The dreamkeepers: Successful teachers of African American children. San Francisco, CA: Jossey Bass Publishers.

Ladson-Billings, G. (2014). Culturally relevant pedagogy 2.0: The remix. Harvard Educational Review, 84(1), p. 74-84.

MEB. (2008). Öğretmen yeterlikleri: Öğretmenlik mesleği genel ve özel alan yeterlikleri. Ankara: Devlet Kitapları Müdürlüğü.

MEB,(2017a). Milli Eğitim İstatistikleri Örgün Eğitim 2016/2017 Y1l. http://sgb.meb.gov.tr/meb_iys_dosyalar/2017_09/08151328_meb_istatistikleri_orgun_egi tim_2016_2017.pdf adresinden erişildi.

MEB. (2017b). Öğretmen yeterlikleri: Öğretmenlik meslĕgi genel ve özel alan yeterlikleri. http://oygm.meb.gov.tr/meb_iys_dosyalar/2017_12/11115355_YYRETMENLYK_MES LEYY_GENEL_YETERLYKLERY.pdf adresinden erişildi.

Memduhoğlu, H. B. (2008). Ulusal, küresel ve örgütsel bağlamda farklılıkları yönetme. Ankara: Pegem Akademi.

Mensah, F. M. (2011). A case for culturally relevant teaching in science education and lessons learned for teacher education. Journal of Negro Education, 80(3), 296-309.

McLaren, P. (1989). Life in schools: An introduction to critical pedagogy in the foundations of education. New York: Longman.

Nam, Y., Roehrig, G., Kern, A., \& Reynolds, B. (2013). Perceptions and practices of culturally relevant science teaching in American indian classrooms. International Journal of Science \& Mathematics Education, 11(1).

Nieto, S. (2002). Language, culture, and teaching: Critical perspectives for a new century. Mahway, NJ: Lawrence Erlbaum. 
Oral, I., \& McGivney, E. J. (2014). Türkiye eğitim sisteminde eşitlik ve akademik başarı, araştırma raporu ve analiz. İstanbul: Sabancı Üniversitesi Yayınları.

Paris, D., ve Alim, H. S. (2017). Culturally sustaining pedagogies: Teaching and learning for justice in a changing world. Teachers College Press.

Paris, D. (2012). Culturally sustaining pedagogy: A needed change in stance, terminology, and practice. Educational Researcher, 41, 93-97.

Ritosa, A. (2017). Interventions Supporting Mathematics and Science In-service and Preservice Teachers' Cultural Responsiveness: A Systematic Literature Review from 19952017.

[Çevrim-içi: https://www.divaportal.org/smash/get/diva2:1104961/FULLTEXT01.pdf], Erişim tarihi: 10 Eylül 2017.

Sleeter, C.E., \& Grant, C.A. (1994). Making choices for multicultural education: Five approaches to race, class, and gender (2nded.). New York: Macmillan.

Tan, A. (2011). Home culture, science, school and science learning: Is reconciliation possible?, Cultural Studies of Science Education, 6, 559-567.

Tuncel, G. (2017). Improving the cultural responsiveness of prospective social studies teachers: An action research. Educational Sciences: Theory \& Practice, 17, 1317-1344

Villegas, A., \& Lucas, T. (2002). Preparing culturally responsive teachers: Rethinking the curriculum. Journal of Teacher Education, 53(1), 20-32.

\section{Summary}

Problem Statement: Turkey, as it has been in every period of history, is a multicultural country, that has hosted many different cultures with its 7 geographical regions and 81 provinces. Also, there are many students who have different disabilities and need special education in Turkey's Educational System. On the other hand, the number of refugee students 
has been increasing dramatically in Turkey, for the last 5 years. According to the reports about equity in education in Turkey, there is achievement gap among students regarding gender, life in rural or urban areas, the number of siblings, home language, school types, socioeconomic levels, and geographic regions. For example, students who come from primarily non-Turkish spoken families have fallen about 2 years behind their peers in reading/writing (literacy) achievement. In line with education for all, equity in education and equality of educational opportunity, it is important to arrange teaching-learning process in such a way that it should include all these students. Thus, in order to be more inclusive in education, it can be said that there is a need for an alternative approach for Turkey and Culturally Relevant Education can be an alternative. But Culturally Responsive/Relevant Education, which advocates consideration of the cultural values in the education system and was put into practice and has been studied by the United States and other countries, has not been studied adequately in Turkey.

Purpose: The aim of this study is to conceptually discuss Culturally Responsive Competencies of Teachers, the Principles of Culturally Responsive/Relevant Pedagogy, and the need for Culturally Responsive/Relevant Education in Turkey's education system in terms of the literature on Culturally Responsive/Relevant Education (CRE).

Method: Based on document analysis of the qualitative research methods, the following keywords were searched in journals indexed in SSCI "culturally relevant/responsive pedagogy and education", "culturally relevant/responsive teachers", "culturally relevant/responsive classroom management" and "culturally relevant/responsive curriculum and instruction".

Findings: CRE is defined as an approach which aims to educate all students intellectually, socially, emotionally and politically while taking into account students' cultural values, cultural differences and references affecting the students' knowledge, skills and 
attitudes; moreover, it is also defined by many researchers as an effective training to meet social and academic needs of students of diverse backgrounds. Therefore, this approach not only highlights academic success but also emphasizes success socially and culturally. Thanks to this approach, students through a critical perspective, will be able to examine the educational process and contents of education and be able to question their role in creating a democratic and multicultural society.

Conclusion: Education is a socio-cultural process and cannot be considered separately from the legislative form of culture in society. Each individual grows in a culture with its own unique values. Therefore, rather than being based on a prototype for training individuals and a single culture (prevailing or dominant culture), education systems, taking into account and respecting cultural differences, should provide equal educational opportunities to all individuals no matter who they are and where they come from. CRE takes into account all students' cultural values, background, experiences, lifestyles, family life, socio-economic levels, and in short, all the elements that make up the culture. And by reflecting these differences in the academic environment, it aims to enable all students to benefit from opportunities equally and to accomplish the learning process. Though creating an appropriate instruction and teaching program for all students is difficult, teachers should use as much different teaching strategies, techniques, culturally diverse materials and evaluation methods as possible in a way to appeal to students with distinct languages, religion, ethnic origin, social and economic status and gender. Considering Turkey's multicultural structure and cultural diversity, it is important to integrate the appropriate courses into education in terms of culturally responsive pedagogy and for researchers to carry out studies upon culturally relevant/responsive education. We offer it is important to make CRE a central part of teacher education, both during initial preparation and during professional development. 
YYÜ Eğitim Fakültesi Dergisi (YYU Journal of Education Faculty), 2018; 15(1):749-789, http://efdergi.yyu.edu.tr

Keywords: Culturally relevant pedagogy, Teachers competencies, Culturally responsive teaching, Culturally Responsive Education in Turkey 